\title{
A streamlined approach to hybrid-chemistry modeling for a low cetane- number alternative jet fuel
}

\author{
Nicolas H. Pinkowski ${ }^{1}$, Yu Wang, Séan J. Cassady, David F. Davidson, Ronald K. Hanson \\ High Temperature Gasdynamics Laboratory, Department of Mechanical Engineering, Stanford \\ University, Stanford, CA 94305-3032, USA
}

\begin{abstract}
The development of renewable, alternative jet fuels presents an exigent challenge to the aviation community. In this work, a streamlined methodology for building computationally efficient kinetic models of real fuels from shock tube experiments is developed and applied to a low cetane-number, broad-boiling alternative jet fuel (termed C-4). A multi-wavelength laser absorption spectroscopy technique was used to determine species time-histories during the high-temperature pyrolysis of C-4, and a batch gradient descent optimization routine built a hybrid-chemistry (HyChem) kinetic model from the measured data. The model was evaluated using combustor-relevant, high-pressure ignition delay time measurements with satisfactory agreement. The present model enables predictive simulations of C-4 in practical environments, while the underlying methodology described here can be readily extended to build kinetic models for a broad range of real fuels of interest.
\end{abstract}

Keywords: Pyrolysis; Jet fuel; Kinetic model; Shock tube; Laser absorption spectroscopy; Convex optimization

\section{Introduction}

Energy-rich petroleum has fueled many of the undeniable advances of the modern, globalized society, including global connectivity through land and air transportation. However, such boons are balanced by the deleterious effects of the massive reliance on chemical propulsion. Toxic and greenhouse gas (GHG) emissions severely degrade air quality and climate change threatens rising global temperatures. In recent years, the world has grappled with the challenge of decarbonizing transportation in a world that relies on it more than ever. Because the vast majority of jet fuels are derived from petroleum, the U.S. Government in 2015 set the ambitious goal of carbon-neutral U.S. jet aviation growth by 2020 [1]. Current efforts to achieve such carbon-neutrality have focused on "drop-in" fuels: alternative hydrocarbon jet fuels with equivalent performance as their petroleum-derived counterparts, but produced with lower life-cycle carbon emissions [2,3]. Examples include alcohol-to-jet (ATJ), FischerTropsch (FT), and biodiesel alternative jet fuels [3].

The National Jet Fuels Combustion Program (NJFCP) has led an effort to develop fundamental modeling and experimental capabilities for designing, testing, and ultimately certifying alternative jet fuels for commercial use [2]. To enable a cohesive body of research, the program has identified a set of test and reference jet fuels to guide fundamental research, model development, and experimental validation [2]. To elucidate the fundamental links between fuel composition and practical performance, a set of test fuels (termed Category $\mathrm{C}$ fuels) were chosen to span a broad scope of physical properties not commonly found in conventional jet fuels. In-depth discussions of the chosen test fuels, denoted C-1

\footnotetext{
${ }^{1}$ Corresponding author: npinkows@stanford.edu
} 
through C-9 (note the use of hyphens for disambiguation), including their unique formulations and properties can be found in [2,4]. Central to the NJFCP's research goals is the development of fundamental kinetic models that effectively integrate into computational simulations to predict the performance of such fuels in practical combustors.

The need for computationally efficient predictive models has impelled recent advances in the approach to kinetic model development. The hybrid-chemistry (HyChem) modeling approach, detailed in [5-8], leverages the two-stage nature of fuel combustion to simplify the development of computational models. Because practical fuels consistently undergo fast pyrolysis well before the slower oxidation of the resulting pyrolytic products, HyChem models separate the pyrolysis and oxidation stages of reaction. They use well-characterized reaction models to describe the oxidation kinetics of the smaller hydrocarbons produced during pyrolysis, and append an additional set of lumped reactions describing the cracking patterns and kinetics of the parent fuel. To date, the HyChem approach has been successfully leveraged to build kinetic models for distillate jet fuels (A-1, A-2, and A-3), synthetic jet fuels (JP-10, C1, and C-5), and distillate rocket fuels (RP2-1 and RP2-2) [5-8]. Because HyChem model development relies on fundamental measurements of fuel cracking patterns, shock tube facilities and laser absorption spectroscopy provide the necessary and ideal experimental tools, namely well-controlled conditions and high measurement bandwidth, for the determination of pyrolysis pathways at combustion-relevant conditions. Specialized laser absorption diagnostics have been developed to measure the time-histories of fuel [9], temperature [10], methane [11], ethylene [12], ethane [13], acetylene [14], aromatics [15], propene [16], and iso-butene [17] during shock tube pyrolysis, and the multi-wavelength speciation methodology proposed by Pinkowski et al. [15] has enabled the simultaneous determination of species mole fractions during the pyrolysis of hydrocarbon fuels.

Emerging new methods to develop HyChem models have been recently proposed that use machine learning approaches to fit models for reference fuels against pre-published shock tube experimental data $[18,19]$. The current study extends these concepts by providing new measurements of a previously uncharacterized fuel and computationally constructing a HyChem model. In this work, a lowcetane number, broad-boiling test fuel (C-4) was studied and a computationally efficient, HyChem model was developed to describe its high-temperature chemical behavior. The multi-wavelength laser absorption spectroscopy technique described in $[13,15,20]$ was employed to characterize the pyrolysis of the fuel in a shock tube at a range of combustion-relevant conditions, and the resulting data was used to inform model development. Consequently, the present study aims to (1) provide species time-histories and early-time yields of the high-temperature pyrolysis of C-4, (2) describe the integration of this data into the development of a hybrid-chemistry kinetic model, and (3) evaluate the resulting model with comparisons to new measurements of global ignition delay times.

\section{Background}

\subsection{Laser absorption spectroscopy}

By leveraging differences in the way matter interacts with light, laser absorption spectroscopy enables the quantitative measurement of species gas properties such as mole fraction, temperature, pressure, and bulk gas velocity. The Beer-Lambert Relation (Eq. 1) describes the attenuation of monochromatic light at wavelength $\lambda$ as it passes through an absorbing medium. The spectral absorbance $\alpha$, the negative logarithm of the fractional transmission $I / I_{0}$, is a function of the number density of the $i^{\text {th }}$ species $\left(n_{i}\right)$, measurement path length $(L)$, and the absorption cross-section ( ) of the $i^{\text {th }}$ species. The absorption cross-section itself is sensitive to temperature, pressure, gas composition, and wavelength, and describes the propensity of a species to absorb light at a given wavelength. It incorporates fundamental 
spectroscopic behavior such as collisional broadening, narrowing, line mixing, and temperaturedependent linestrengths (see [21-23] for more information) into a single term at a single wavelength of light.

$$
\alpha=-\ln \left(\frac{I}{I_{0}}\right)=n_{i} \quad L \quad \text { Eq. } 1
$$

Eq. 1 describes a system with only one absorbing species at wavelength $\lambda$. In a practical pyrolysis experiment, however, many such species may be present, and the measured absorbance represents a composite summation over contributions from each absorber. Isolating and measuring individual species from such blended absorption presents a challenge in laser spectroscopy studies. To overcome this challenge, Pinkowski et al. $[13,15]$ have developed and demonstrated a multi-wavelength speciation methodology in which a range of simultaneously probed wavelengths, in concert with a matrix of cross-section measurements, untangle the unique spectral shapes of each absorber and isolate the mole fractions of the contributing species. This methodology, employed here, was first developed in [15] and subsequently demonstrated in the pyrolysis of 1-butene [13] and additional jet fuels [20].

\subsection{Shock tube facilities}

Fundamentally, a shock tube consists of a long, closed tube partitioned by a sacrificial diaphragm into two separate regions [24]. The 'driven' region is filled with a low-pressure test gas mixture, while the other ('driver') region is pressurized until the diaphragm bursts. A shock wave generated by the pressure differential travels down the length of the tube and reflects off the end-wall, shock-heating and pressurizing the test gas to well-controlled measurement conditions. A nominally stagnant test region of high-temperature and pressure forms near the end of the shock tube, and test times typically last between 1 and $10 \mathrm{~ms}[25,26]$.

In the present work, pyrolysis and ignition delay time measurements spanned three pressuredriven, stainless steel shock tubes with driven-section internal diameters (I.D.) of $13.97 \mathrm{~cm}, 14.13 \mathrm{~cm}$, and $5 \mathrm{~cm}$. The $13.97 \mathrm{~cm} \mathrm{I.D.} \mathrm{facility} \mathrm{(described} \mathrm{in} \mathrm{[27])} \mathrm{and} 14.13 \mathrm{~cm}$ facility (see [13]) were designed to accommodate pressures up to $10 \mathrm{~atm}$, while the $5 \mathrm{~cm}$ I.D. shock tube [28] was developed specifically for high-pressure experiments up to $500 \mathrm{~atm}$. The initial test gas temperature, pressure, and composition, along with measurements of the incident shock velocity inferred from pressure transducers located along each driven section, were used to determine the thermodynamic state of the gas across both the incidentand reflected-shock waves. Such test conditions were calculated with software developed in [29] using the shock-jump relations and assumptions of frozen chemistry and a vibrationally equilibrated system. Additional details supporting these assumptions can be found in [30].

\subsection{Laser systems}

In total, six lasers systems, emitting monochromatic light at nine wavelengths in the $3 \mu \mathrm{m}$ and 10 $\mu \mathrm{m}$ regions, were aligned through one of the three shock tubes to collect absorbance measurements. Due to the limited optical lines-of-sight through each shock tube, multiple iterations of optical configurations were developed on each facility to acquire measurements at all wavelengths for a range of conditions. Diagnostic lasers and their wavelengths were chosen for strong sensitivity to specific species anticipated to be present in the system. Table 1 outlines the selected wavelengths, their target species, and the lasers used for each in this work. Bristol 721 or 771 spectrum analyzers were used to confirm the wavelengths of each laser between successive experiments. 
Table 1. Selected wavelengths and their target species used to determine mole fractions of C-4 fuel pyrolysis in the present work.

\begin{tabular}{|l|l|l|}
\hline Wavelength & Target Species & Laser \\
\hline $\begin{array}{l}3.1758 \mu \mathrm{m} \text { (online)/3.175595 } \\
\mu \mathrm{m} \text { (offline) }\end{array}$ & $\mathrm{CH}_{4}[11]$ & $\begin{array}{l}\text { Tunable interband cascade laser } \\
\text { (ICL) }\end{array}$ \\
\hline $3.283 \mu \mathrm{m}$ & $\mathrm{C}_{6} \mathrm{H}_{6} / \mathrm{C}_{7} \mathrm{H}_{8}[15]$ & Tunable ICL \\
\hline $3.3519 \mu \mathrm{m}$ & $\mathrm{C}_{2} \mathrm{H}_{6}[13]$ & Tunable ICL \\
\hline $3.41 \mu \mathrm{m}$ & Fuel [9] & Tunable ICL \\
\hline $\begin{array}{l}10.532 \mu \mathrm{m} \text { (online) } / 10.675 \mu \mathrm{m} \\
\text { offline) }\end{array}$ & $\mathrm{C}_{2} \mathrm{H}_{4}[12,31]$ & $\mathrm{CO}_{2}$ gas laser \\
\hline $10.958 \mu \mathrm{m} / 11.345 \mu \mathrm{m}$ & $\mathrm{C}_{3} \mathrm{H}_{6}[16] / \mathrm{i}-\mathrm{C}_{4} \mathrm{H}_{8}[17]$ & $\begin{array}{l}\text { External cavity quantum } \\
\text { cascade laser (EC-QCL) }\end{array}$ \\
\hline
\end{tabular}

Laser wavelength selection was informed by supporting flow reactor measurements (described in Appendix B). The laser systems were chosen to target all major species observed. However, some species appear in trace amounts in the flow reactor results that are not accounted for with the present spectroscopic sensor suite. The largest of these are acetylene, propyne, propadiene, and 1,3-butadiene (see Fig. B.1 in Appendix B). Spectroscopic measurements require sufficient optical absorbance for species detection. As evidenced by Eq. 1, absorbance at a given wavelength is sensitive both to a species' cross-section and to its mole fraction. Because both the mole fractions of these possible interferers (Fig. B.1) and their cross-sections at the chosen wavelengths (Fig. B.2) are small, they are not expected to contribute meaningful interference to the measured absorbance time-histories.

Figure 1(a) shows a representative schematic of a shock tube facility with laser diagnostics aligned for measurement. Light from each laser crosses the measurement plane of the shock tube through two optical ports and is subsequently collected by a photovoltaic detector. Narrow-bandpass spectral filters placed before the detectors attenuate unwanted emission from the high-temperature test gas. For laser light in the $3 \mu \mathrm{m}$ region, optical access through the tube was provided by sapphire windows and transmitted light was focused onto liquid nitrogen-cooled photovoltaic indium antimonide detectors. In the 10-12 $\mu \mathrm{m}$ region, zinc selenide windows offered optical access across the shock tube, and light was collected by thermoelectrically cooled photovoltaic mercury cadmium telluride detectors. Fig. 1(b) shows an example laser absorption measurement of species time-histories during the pyrolysis of $0.4 \% \mathrm{C}-4$ fuel at $1304 \mathrm{~K}, 1.53 \mathrm{~atm}$. Absorbance time-histories at wavelengths $3.41 \mu \mathrm{m}$, sensitive to fuel, and 11.345 $\mu \mathrm{m}$, sensitive to iso-butene, are shown. Measurement time-zero is defined to coincide with the passage of the reflected shock wave across the measurement plane.

\subsection{C-4 test fuel}

In support of alternative jet fuel studies, six Category $\mathrm{C}$ test fuels were chosen by NJFCP to span a wide range of unusual chemical and physical properties [4]. The fuel C-4, in particular, is a synthetic blend of two other fuels: 60\% Sasol Iso-Paraffinic Kerosene (IPK) and 40\% Gevo Alcohol-to-Jet (ATJ). Gevo ATJ is a bimodal fuel primarily composed of C12 and C16 iso-paraffins with a very low cetane number of 17.1 [4]. Because of its extreme bimodal boiling behavior, Gevo ATJ was blended with another low-cetane fuel, Sasol IPK, to produce a test fuel (C-4) that exhibits a more broad-boiling fuel profile. Table 2 shows selected global properties of C-4, compared with a reference fuel for Jet A (A-2), Gevo ATJ alone (C-1), and another alternative jet fuel (C-5) known for its flat-boiling behavior. Figure 2 
compares the fuel compositions of a reference Jet A fuel with C-4. As a fuel almost entirely composed of iso-paraffins, C-4 is expected to display distinct behavior as it undergoes pyrolysis and combustion.

Table 2. Thermochemical properties of Jet A (denoted A-2), Gevo ATJ (denoted C-1), a mixture of Sasol IPK and Gevo ATJ (denoted C-4), and a broad-boiling alternative jet fuel (C-5). Molecular weights (MW) and lower heating values (LHV) are sourced from [4], the average formulae $\left(\mathrm{C}_{\mathrm{x}} \mathrm{H}_{\mathrm{y}}\right), \mathrm{H}_{\mathrm{v}}$, and $\Delta_{f} H^{\circ}{ }_{298}$ are sourced from [5], and derived cetane number from [4].

\begin{tabular}{|c|c|c|c|c|c|c|c|}
\hline Fuel & Description & $\begin{array}{l}\text { Average } \\
\text { Formula }\end{array}$ & $\begin{array}{l}\text { MW } \\
\text { (g/mol) }\end{array}$ & $\begin{array}{l}\text { LHV } \\
\text { (MJ/kg) }\end{array}$ & $\begin{array}{l}\mathbf{H}_{\mathbf{v}} \\
(\mathrm{MJ} / \mathrm{kg})\end{array}$ & $\begin{array}{r}\Delta_{f} H^{\circ}{ }_{298} \\
(\mathrm{kcal} / \mathrm{mol})\end{array}$ & $\mathbf{D C N}^{\mathrm{a}}$ \\
\hline Jet A (A-2) & $\begin{array}{l}\text { Highly varied mix of aromatics, } \\
\text { iso-paraffins, n-paraffins, and } \\
\text { cyclo-paraffins }\end{array}$ & $C_{11.4} H_{21.7}$ & 158.6 & 43.12 & 0.36 & -66.8 & 47.0 \\
\hline $\begin{array}{ll}\text { Gevo } & \text { ATJ } \\
(\text { C-1 }) & \end{array}$ & $\begin{array}{l}61 \text { wt. } \% \text { pentamethyl-heptane, } \\
17 \text { wt. \% highly branched C12 } \\
\text { iso-paraffins, } 8 \text { wt. \% } \\
\text { heptamethyl-nonane, and high- } \\
\text { branched C16 iso-paraffins }\end{array}$ & $C_{12.5} H_{27.1}$ & 178.0 & 43.90 & 0.35 & -81.9 & 17.1 \\
\hline $\begin{array}{l}\text { Sasol/Gevo } \\
(\mathrm{C}-4)\end{array}$ & $\begin{array}{l}\text { ( 40\% Gevo, } 60 \% \text { Sasol IPK) } \\
24 \text { wt. \% pentamethyl-heptane, } 7 \\
\text { wt. \% less highly branched ( } 3 \text { \& } \\
\text { 4) C12 iso-paraffins; } 3 \text { wt. } \% \\
\text { heptamethyl-nonane. From } \\
\text { Sasol: 1- to 4- branched iso- } \\
\text { paraffins }\end{array}$ & $C_{11.4} H_{24.7}$ & 162.2 & 43.79 & 0.35 & -79.0 & 28 \\
\hline (C-5) & $\begin{array}{l}74 \% \text { C10 iso-paraffins, } 26 \% \\
\text { 1,3,5-trimethyl benzene. Very } \\
\text { flat boiling range }\end{array}$ & $\mathrm{C}_{9.7} \mathrm{H}_{18.7}$ & 139.3 & 42.98 & 0.38 & -46.6 & 39.6 \\
\hline
\end{tabular}

\section{Pyrolysis speciation measurements}

\subsection{Experimental preparation}

Highly dilute molar mixtures of $0.4 \%$ jet fuel in argon were used in all high-temperature speciation and ignition delay time measurements. Care was taken to ensure that the fuel did not condense out of the test gas between the time of initial mixture preparation and the arrival of the reflected shock wave. In two of the three shock tubes, jacketed heaters on the shock tube driven-gas sections, heated mixing tanks, and heated gas-delivery manifolds were used to maintain the fuel in the vapor phase [32]. In the third (unheated) shock tube, mixture preparation was completed at low pressures inside of the shock tube itself, without the use of a high-temperature mixing tank. To avoid fuel condensation in the unheated driven-gas section of this shock tube, all mixtures were prepared using a diffusive-mixing process over 2-3 hours at low total pressures of 50-100 Torr. The compositions of all test-gas mixtures were validated by an independent laser absorption diagnostic at $3.41 \mu \mathrm{m}$ immediately prior to each shock tube experiment. Preshock measurements of the fuel mole fraction were within $\pm 5 \%$ of the manometrically prepared samples.

\subsection{Results}

\subsubsection{Laser absorbance measurements}


In total, two subsets of multi-wavelength pyrolysis data for C-4 were collected using five and nine wavelengths in two different shock tubes. The five-wavelength subset yielded mole fractions of ethylene, propene, and iso-butene using the measured absorbance at wavelengths $10.532 \mu \mathrm{m}, 10.675 \mu \mathrm{m}, 10.958$ $\mu \mathrm{m}, 11.345 \mu \mathrm{m}$, and $3.41 \mu \mathrm{m}$ across a range of temperatures from 1120-1470 K. However, at $1470 \mathrm{~K}$, due to rapid C-4 decomposition, only selected absorbance time-histories were used. The nine-wavelength measurement subset used all wavelengths in Table 1 to yield mole fractions for eight species (methane, ethane, ethylene, propene, iso-butene, benzene, toluene, and C-4) at two temperatures (1135 K and 1225 $\mathrm{K})$. Representative pressure- and path length-normalized absorbance traces are presented for $1225 \mathrm{~K}$ in Fig. 3. The absorbance time-histories of Fig. 3 were produced from an interpolation of several independent shock tube experiments to the uniform condition of $1225 \mathrm{~K}$. The process used to generate the interpolated absorbance traces, and its corresponding uncertainty, has been previously discussed in the literature [13].

\subsubsection{Inferred mole fraction measurements}

Constrained convex optimization was used to calculate mole fractions from the absorbance measurements. A Beer-Lambert system was formulated in the form of Eq. 2 including a vector of $N$ pressure-and path-length normalized absorbances, $\mathbf{b} \in R^{N}$, a vector of $M$ species mole fractions, $\mathbf{x} \in R^{M}$, a matrix of absorption cross-sections $\mathbf{K} \in R^{N \times M}$ and a weighting parameter matrix $\mathbf{W} \in R^{N \times M}$. Several convex constraints were employed, including elemental constraints of hydrogen and carbon and the assumption that a proportionate amount of carbon goes to both benzene and toluene. The diagonal weighing matrix $W$ accounts for system heteroscedasticity and provides a method to devalue wavelengths with potential interfering absorbance [13].

$$
\text { Minimize: } \quad\|\mathbf{W}(\mathbf{K x}-\mathbf{b})\|_{2}^{2}
$$

Subject to:

1) $\vec{x} \geq 0$

2) The calculated number of hydrogen and carbon atoms must not exceed the known amount of carbon loaded into the shock tube.

The absorption cross-section matrix includes 81 temperature- and (for methane and ethylene) pressure-dependent cross-section correlations for each species at each wavelength. All cross-section correlations, except for those of the fuel C-4, have been previously characterized [13,15]. Absorption cross-section measurements for C-4 are included in Appendix A. The convex absorbance system was solved at each instance in time using CVX in Matlab [33,34]. Due to an anticipated temperature decrease over the test time, estimated temperature profiles from $\mathrm{C}-1$ HyChem model were used to account for changing absorption cross-sections during endothermic fuel pyrolysis. Ultimately, temperature was included in the uncertainty analysis and the results were found to be insensitive to its contribution. Representative mole fractions measurements from the high-temperature thermal decomposition of $0.4 \%$ C-4 in argon are presented in Fig. 4 (a-f) and consistent with the independent flow reactor data included in Appendix B. 
Two additional constraints from elemental balance were used in the mole fraction calculations: that the atomic balance of measured carbon and hydrogen not exceed $100 \%$ at any time. While not altogether necessary, these constraints ensure physically valid results. For the nine-wavelength measurements (within expected uncertainty), the system showed the tendency to completely fill the carbon constraint. This result agrees well with flow reactor data (Appendix B), which shows measured species capturing $97 \%$ of the system's total carbon. Conversely, the percentage of captured hydrogen was observed to decay as the system evolves, a phenomenon suggesting the formation of hydrogen gas as a pyrolysis product. Although not quantified here, the expected hydrogen from an elemental balance agrees well with simulated profiles from other Category $\mathrm{C}$ jet fuels. Because current aromatics laser diagnostics cannot yet distinguish between toluene and benzene, the measured carbon attributed to aromatics in the system was equally split between benzene and toluene. This assumption is supported by the measurements of Corporan et al. [35]. Ultimately, because the amounts of both benzene and toluene are small, this constraint did not impact model development. To account for wavelength-dependent heteroscedasticity, the method described in Pinkowski et al. [13], was employed to set the diagonal weighting matrix $W$ based on the expected spectra of potential interferers $\left(\mathrm{C}_{2} \mathrm{H}_{2}, 1,3-\mathrm{C}_{4} \mathrm{H}_{6}, a-\mathrm{C}_{3} \mathrm{H}_{4}\right.$, p$\mathrm{C}_{3} \mathrm{H}_{4}$, and 1- $\mathrm{C}_{4} \mathrm{H}_{8}$ for example). The most prevalent interference would occur from such small species in the $3 \mu \mathrm{m}$ region (see Fig. B.2, notably the $1-\mathrm{C}_{4} \mathrm{H}_{8}$ cross-section). Correspondingly, the weighting matrix devalues wavelengths such as $3.3519 \mu \mathrm{m}$ and $3.392 \mu \mathrm{m}$ to desensitize the solution to spurious interference at any particular wavelength. Such a weighting scheme does, however, result in increased overall mole fraction uncertainties (especially in minor species) based on the rigorous multi-wavelength uncertainty quantification method described in [13].

\section{Hybrid-chemistry model optimization}

In order to build a hybrid-chemistry kinetic model from high-temperature pyrolysis data, the lumpedpyrolysis reaction rates and branching ratios describing a fuel's cracking patterns must be adjusted until modeled species time-histories agree with experimental data. In this work, 11 such model parameters were numerically optimized over the full set of laser-based speciation data to develop a complete hybridchemistry model describing C-4 fuel. This model was then tested using ignition delay time measurements at high-pressure conditions relevant to practical aircraft engines. This section describes the formulation, numerical optimization routine, and experimental evaluation of the resulting model. Using methods common to machine/statistical learning, three steps were used to train the model from pyrolysis data: 1) definition of the model and its independent parameters, 2) selection of an optimization cost function, and 3) choice of search strategy in the multi-dimensional parameter space. Ultimately, the authors believe this numerical, supervised learning approach is one of the most robust methods to optimize a HyChem model using a wide range of experimental results.

\subsection{The hybrid-chemistry (HyChem) model}

A HyChem kinetic model leverages the observed pyrolysis behavior of parent fuels to simplify chemical complexity. In the combustion process, large fuels undergo reaction in two primary stages: first, they thermally decompose into smaller hydrocarbons, then these smaller fuels react to form combustion products [5-8]. Thermal decomposition occurs even when oxygen is present and can accelerate due to the production of $\mathrm{OH}$ and $\mathrm{HO}_{2}$ during fuel pyrolysis. A HyChem model describes the thermal decomposition of a fuel through seven lumped-pyrolysis reactions (R1-7 below), which are then concatenated with a foundational-chemistry mechanism. $\mathrm{R}$ represents species $\mathrm{H}, \mathrm{CH}_{3}, \mathrm{OH}, \mathrm{O}_{2}, \mathrm{HO}_{2}$, and $\mathrm{O}$, the Greek letters $(\alpha, \beta, \chi, \lambda$, and $\gamma)$ denote independent stoichiometric parameters that are to be 
determined experimentally, and $e_{d}$ and $e_{a}$ are dependent stoichiometric parameters derived from hydrogen and carbon elemental conservation [6]. In this work, the detailed USC Mech II, used as the foundational kinetic model, was augmented to include the additional seven hybrid-chemistry reactions. The sum of the alkene and aromatics $\left(\Sigma_{\text {alkenes }}\right.$ and $\left.\Sigma_{\text {aro }}\right)$ used in the hybrid-chemistry reactions are provided by Eq. 3-4.

$$
C_{m} H_{n} \rightarrow e_{d} \Sigma_{\text {alkenes }}+b_{d} \Sigma_{\text {aro }}+\alpha H+(2-\alpha) \mathrm{CH}_{3}
$$

$C_{m} H_{n}+H \rightarrow(H)+\gamma C H_{4}+e_{d} \Sigma_{\text {alkenes }}+b_{d} \Sigma_{\text {aro }}+\beta H+(1-\beta) C H_{3}$

$\mathrm{C}_{m} \mathrm{H}_{n}+\mathrm{CH}_{3} \rightarrow\left(\mathrm{CH}_{4}\right)+\gamma \mathrm{CH}_{4}+e_{d} \Sigma_{\text {alkenes }}+b_{d} \Sigma_{\text {aro }}+\beta H+(1-\beta) \mathrm{CH}_{3}$

$\mathrm{C}_{m} \mathrm{H}_{n}+\mathrm{OH} \rightarrow(\mathrm{OH})+\gamma \mathrm{CH}_{4}+e_{d} \Sigma_{\text {alkenes }}+b_{d} \Sigma_{\text {aro }}+\beta H+(1-\beta) \mathrm{CH}_{3}$

$\mathrm{C}_{m} \mathrm{H}_{n}+\mathrm{O}_{2} \rightarrow\left(\mathrm{O}_{2}\right)+\gamma \mathrm{CH}_{4}+e_{d} \Sigma_{\text {alkenes }}+b_{d} \Sigma_{\text {aro }}+\beta \mathrm{H}+(1-\beta) \mathrm{CH}_{3}$

$\mathrm{C}_{m} \mathrm{H}_{n}+\mathrm{HO}_{2} \rightarrow\left(\mathrm{HO}_{2}\right)+\gamma \mathrm{CH}_{4}+e_{d} \Sigma_{\text {alkenes }}+b_{d} \Sigma_{\text {aro }}+\beta \mathrm{H}+(1-\beta) \mathrm{CH}_{3}$

$C_{m} H_{n}+O \rightarrow(O)+\gamma C H_{4}+e_{d} \Sigma_{\text {alkenes }}+b_{d} \Sigma_{\text {aro }}+\beta H+(1-\beta) C H_{3}$

$\Sigma_{\text {alkenes }}=C_{2} H_{4}+\lambda_{3} C_{3} H_{6}+\lambda_{4,1} 1 C_{4} H_{8}+\lambda_{4, i} i C_{4} H_{8}$

$\Sigma_{\text {aro }}=\chi C_{6} H_{6}+(1-\chi) C_{7} H_{8}$

Eq. 4

Reactions 1-7 each proceed with rate constants of the form provided in Eq. 5:

$k_{i}=B_{i} T^{m_{i}} \exp \left(-\frac{E_{b, i}}{R_{u} T}\right) \quad$ for $\mathrm{i}=1-7$

Eq. 5

While substantially less complex than detailed modeling approaches for large fuels [36-39], the formulation of a hybrid-chemistry model still requires the determination of a large number of unknowns. Table 3 provides an overview of the variables required for model formulation and the methods employed to determine them. For many parameters, such as $\lambda_{4,1}$ (the relative ratio between 1-butene and ethylene), appropriate assumptions can be made to reduce the total number of unknowns in the system. Due to structural similarities of the fuel, reaction rates for R4-R7 were adopted from [5], which are consistent with the $n$-heptane and $n$-dodecane rate constants employed in the JetSurF mechanism [35,36].

Table 3. An overview of the independent parameters required for the formulation of a hybrid-chemistry kinetic model. The 11 parameters determined through model optimization are indicated.

\begin{tabular}{cll}
\hline Variable & Description & Determination \\
\hline$\lambda_{3}$ & {$\left[\mathrm{C}_{3} \mathrm{H}_{6}\right] /\left[\mathrm{C}_{2} \mathrm{H}_{4}\right]$} & Model optimization \\
\hline$\lambda_{4, \mathbf{1}}$ & {$\left[1-\mathrm{C}_{4} \mathrm{H}_{8}\right] /\left[\mathrm{C}_{2} \mathrm{H}_{4}\right]$} & Measured to be approximately zero \\
\hline
\end{tabular}




\begin{tabular}{cll}
\hline$\lambda_{4, \boldsymbol{i}}$ & {$\left[\mathrm{i}-\mathrm{C}_{4} \mathrm{H}_{8}\right] /\left[\mathrm{C}_{2} \mathrm{H}_{4}\right]$} & Model optimization \\
\hline $\boldsymbol{\alpha}$ & {$\left[\mathrm{C}_{6} \mathrm{H}_{6}\right] /\left(\left[\mathrm{C}_{6} \mathrm{H}_{6}\right]+\left[\mathrm{C}_{7} \mathrm{H}_{8}\right]\right)$} & Estimated to be $0.5[5,6]$ \\
\hline $\boldsymbol{\alpha}$ & $\mathrm{H}$ atoms produced by C-C fission of fuel & Model optimization \\
\hline $\boldsymbol{\beta}$ & $\mathrm{H}$ atoms produced by H-abstraction reactions & Model optimization \\
\hline $\boldsymbol{\gamma}$ & $\mathrm{CH}_{4}$ stoichiometric coefficient & Model optimization \\
\hline $\boldsymbol{B}_{\mathbf{1}-\mathbf{3}}$ & $\mathrm{R} 1-\mathrm{R} 3$ rate constant parameters & Model optimization \\
\hline $\boldsymbol{E}_{\boldsymbol{b}, \mathbf{1}-\mathbf{3}}$ & $\mathrm{R} 1-\mathrm{R} 3$ rate constant parameter & Model optimization \\
\hline${ }^{1}$ The model was fit to pyrolysis measurements over a relatively small temperature range, and hence assumed \\
Arrhenius form. Accordingly, non-Arrhenius behavior $\left(m_{1-7}\right)$ was \\
reactions [5,38,39].
\end{tabular}

Pyrolysis time-histories were fit over a $200 \mathrm{~K}$ temperature range and Arrhenius behavior was assumed $\left(m_{1-7}=0\right)$ for the fitting process. However, the final model is presented in non-Arrhenius format with previous hybrid-chemistry models offering estimates for the modified Arrhenius expression (Eq. 5).

\subsection{Loss criterion selection}

When fitting the model to pyrolysis species time-history measurements, the performance of the model was assessed using the L2 norm of the difference in the measured vs. predicted mole fraction vectors. Equation 6 mathematically describes the selected cost function $(C)$ summed over $N$ species and $M$ temperatures. The variables $\boldsymbol{x}_{\boldsymbol{j}, \boldsymbol{i}}$ and $\widehat{\boldsymbol{x}}_{\boldsymbol{j}, \boldsymbol{i}}$ represent the measured and predicted mole fraction of species $i$ for test conditions $j$.

$$
C=\sum_{j=1}^{M} \sum_{i=1}^{N}\left\|\mathbf{x}_{\mathbf{j}, \mathbf{i}}-\hat{\mathbf{x}}_{\mathbf{j}, \mathbf{i}}(y)\right\|_{2}
$$

\subsection{Optimization strategy}

A batch gradient descent method was used to determine the optimal values for the 11 independent parameters shown in Table 3. For a given set of input parameters, denoted by vector $\mathbf{y}$, a reaction was simulated and a cost $C$ calculated. Inputs $\boldsymbol{y}$ were specified as vector elements between -1 and 1 , and randomly initialized. The inputs $\boldsymbol{y}$ passed through sigmoid functions that mapped each input to a hybrid chemistry parameter. The sigmoid input layer provided a method to constrain the maximum and minimum values for parameters within reasonable bounds. The stoichiometric parameters $\alpha, \beta$, and $\gamma$ were constrained between 0 and 1 , and $\lambda_{3}$ and $\lambda_{4 i}$ were constrained between 0 and 3 . Among rate parameters for Reactions 1-3, the activation energies were constrained between 74 to $80 \mathrm{kcal} / \mathrm{mol}, 8$ to 13 $\mathrm{kcal} / \mathrm{mol}$, and 12 to $20 \mathrm{kcal} / \mathrm{mol}$, respectively. The A parameters were constrained from $5 \times 10^{16}$ to $2 \times 10^{18}$ $1 / \mathrm{s}, 2 \times 10^{14}$ to $5 \times 10^{15} \mathrm{~cm}^{3} / \mathrm{mol} / \mathrm{s}$, and $6 \times 10^{12}$ to $5 \times 10^{14} \mathrm{~cm}^{3} / \mathrm{mol} / \mathrm{s}$, for reactions $1-3$ respectively. Of note, reactions R1-R3 were computationally constrained to fall within kinetically reasonable bounds.

The chemical kinetic differential equations were solved using open-source Cantera software that enabled iterative execution and refinement of the model [40]. A zero-dimensional, constant-pressure reactor was used to simulate high-temperature pyrolysis of C-4. Thermochemical properties from the literature were used in all kinetic simulations [41]. Pyrolysis of C-4 in argon was simulated and the cost function $C$ calculated at each of the measurement conditions in the pyrolysis dataset (see Fig. 4). Partial 
derivatives, $\partial C / \partial \boldsymbol{y}$, of the cost function with respect to each component of the input vector, were then estimated through a forward-perturbation-based numerical approximation.

An iteration-dependent learning rate, $\psi$, was used to update all parameters in the input variable $y$ along the direction of the steepest decline of the cost function $C$. Updates were performed on a logarithmic scale using Eq. 7. Equation 8 describes how the learning rate $\psi$ decreased with every iteration (iter) from one until a specified maximum iteration, iter $_{\text {max }}$. Convergence of the system is evidenced in Fig. 5, as the cost function $C$ decreases to a stable point over 100 iterations. A synthesis of the search strategy is provided in Algorithm 1.

$$
\begin{aligned}
\ln \left(y_{i, \text { new }}\right) & =\ln \left(y_{i}\right)-\ln \left(1-\operatorname{sign}\left(\frac{\partial C}{\partial y_{i}}\right) \psi\right) \\
\psi & =\frac{1}{4} \exp \left(-\frac{\text { iter }}{\text { iter }_{\text {max }}}\right)
\end{aligned}
$$

\subsection{Model results}

The resulting hybrid-chemistry parameters from the converged batch gradient descent algorithm are presented in Table 4. Figure 6 provides a comparison between the measured and modeled mole fractions across five representative conditions. Measured and modeled species yields at $0.5 \mathrm{~ms}$ are provided in Fig. 7 for the most abundant species: ethylene, propene, and iso-butene. Yields are defined at $0.5 \mathrm{~ms}$ for the mole fraction of each species normalized by the initial mole fraction of C-4. With few exceptions, good agreement is observed across a wide range of temperatures. While excellent agreement is obtained from 1120 to $1230 \mathrm{~K}$, the predicted ethylene time-histories diverge somewhat between the model and experimental data for the highest temperature of $1322 \mathrm{~K}$. Ultimately, due to the rapid decomposition of C4 , reactions above $1300 \mathrm{~K}$ are impacted further by pyrolysis of fuel fragments. Improvements in the foundational fuel chemistry model, especially in the kinetics of $\mathrm{i}-\mathrm{C}_{4} \mathrm{H}_{8}$, will likely improve agreement at these high temperatures. Uncertainty in the mole fraction measurements was determined rigorously using the methods described in [13]. This process involves numerically perturbing each cross-section correlation, absorbance time-history, weighting parameter, and the temperature profile and determining their individual contributions to uncertainty. Here, mole fraction uncertainties range between $10-20 \%$, arising primarily from absorbance measurements at $10.532 \mu \mathrm{m}, 10.958 \mu \mathrm{m}$, and $11.345 \mu \mathrm{m}$. The uncertainty inherent in modeled pyrolysis mole fractions is conservatively estimated as $30 \%$, a value dominated primarily by uncertainty induced by inferring mole fractions from raw absorbance $(10-20 \%)$ and from the HyChem optimization routine. The HyChem contribution to uncertainty (20\%) was estimated from the discrepancy between measurement and model at a representative condition: propene mole fraction at $1 \mathrm{~ms}$ at $1231 \mathrm{~K}$ (see Fig. 6(d)). This value is comparable to uncertainties reported in previous HyChem models [6].

Table 4. Resulting hybrid-chemistry parameters from the batch gradient descent algorithm for C-4 compared to two existing models for other Category C fuels, C-1 [7] and C-5 [42].

\begin{tabular}{c|l|l|l} 
Variable & C-4 model & C-1 model & C-5 model \\
\hline$\lambda_{3}$ & 2.40 & 2.32 & 0.30
\end{tabular}




\begin{tabular}{|c|c|c|c|c|c|c|c|c|c|}
\hline$\lambda_{4,1}$ & \multicolumn{3}{|l|}{0.00} & \multicolumn{3}{|l|}{0.00} & \multicolumn{3}{|l|}{0.04} \\
\hline$\lambda_{4, i}$ & \multicolumn{3}{|l|}{1.86} & \multicolumn{3}{|l|}{10.00} & \multicolumn{3}{|l|}{0.05} \\
\hline$\gamma$ & \multicolumn{3}{|l|}{0.50} & \multicolumn{3}{|l|}{0.0} & \multicolumn{3}{|l|}{0.01} \\
\hline$\alpha$ & \multicolumn{3}{|l|}{1.00} & \multicolumn{3}{|l|}{1.06} & \multicolumn{3}{|l|}{1.00} \\
\hline$\beta$ & \multicolumn{3}{|l|}{0.61} & \multicolumn{3}{|l|}{0.98} & \multicolumn{3}{|l|}{0.65} \\
\hline$\chi$ & \multicolumn{3}{|l|}{0.50} & \multicolumn{3}{|l|}{0.00} & \multicolumn{3}{|l|}{0.26} \\
\hline $\mathbf{R x n}^{\mathrm{a}}$ & B & $\mathbf{m}$ & $\mathbf{E}_{\mathbf{b}}$ & B & $\mathbf{m}$ & $\mathbf{E}_{\mathrm{b}}$ & B & m & $\mathbf{E}_{\mathbf{b}}$ \\
\hline $\mathbf{k}_{1}$ & 5.17E26 & -2.58 & $8.49 \mathrm{E} 4$ & $2.83 \mathrm{E} 26$ & -2.58 & $8.02 \mathrm{E} 4$ & $1.47 \mathrm{E} 26$ & -2.66 & 8.82E4 \\
\hline $\mathbf{k}_{2}$ & $8.56 \mathrm{E} 6$ & 2.4 & $4.61 \mathrm{E} 3$ & $8.72 \mathrm{E}-5$ & 2.40 & $2.58 \mathrm{E} 3$ & $7.66 \mathrm{E}-2$ & 4.76 & 1.29 \\
\hline $\mathbf{k}_{3}$ & $2.50 \mathrm{E}-7$ & $5.95^{\mathrm{b}}$ & 4.95E2 & 4.64 & 3.46 & $4.60 \mathrm{E} 3$ & $4.76 \mathrm{E}-7$ & 5.95 & $4.75 \mathrm{E} 3$ \\
\hline $\mathbf{k}_{4}$ & $2.96 \mathrm{E} 9$ & 1.02 & 2.13E2 & $4.88 \mathrm{E} 10$ & 0.51 & 64.00 & $3.55 \mathrm{E} 10$ & 1.02 & 2.13E2 \\
\hline $\mathbf{k}_{5}$ & $1.78 \mathrm{E} 15$ & 0.06 & $4.75 \mathrm{E} 4$ & 1.49E15 & 0.00 & $4.30 \mathrm{E} 4$ & $2.55 \mathrm{E} 14$ & 0.06 & $4.75 \mathrm{E} 4$ \\
\hline $\mathbf{k}_{6}$ & $6.98 \mathrm{E} 4$ & 2.94 & $1.43 \mathrm{E} 4$ & $9.03 \mathrm{E} 3$ & 2.77 & $1.05 \mathrm{E} 4$ & $2.33 \mathrm{E} 4$ & 2.94 & $1.43 \mathrm{E} 4$ \\
\hline $\mathbf{k}_{7}$ & 8.94E1 & 3.86 & 7.65E2 & $7.85 \mathrm{E} 4$ & 2.50 & $1.11 \mathrm{E} 3$ & 8.94E1 & 3.86 & 7.65E2 \\
\hline
\end{tabular}

${ }^{\text {a }}$ Rate parameters $\left(\boldsymbol{k}=\boldsymbol{B} \boldsymbol{T}^{\boldsymbol{m}} \boldsymbol{e}^{-\boldsymbol{E}_{\boldsymbol{b}} / \boldsymbol{R T}}\right)$ with $\mathrm{R}$ in units of cal/molK and the activation energy $\mathrm{E}_{\mathrm{b}}$ in units of $\mathrm{cal} / \mathrm{mol}$

${ }^{\mathrm{b}}$ This value, estimated from C-5, was found to yield results consistent with the current experimental results.

${ }^{\mathrm{c}}$ Not included in the optimization process are rates for reactions 4-7, which were approximated from $[5,38,39]$.

\subsection{Model evaluation against ignition delay}

C-4 ignition delay time (IDT) data was used to assess the ability of the present hybrid-chemistry model, formulated only from high-temperature pyrolysis measurements, to effectively capture global chemical behavior of C-4 during combustion. The resulting measured and modeled IDTs are shown in Fig. 8. Here, IDT is defined as the residence time between time-zero and a time where the maximum slope of the $\mathrm{OH}^{*}$ time-history is extrapolated back to zero. Modeled conditions assumed a constant volume reactor [43]. Good agreement between the model and the measurements was achieved for conditions below $1100 \mathrm{~K}(1000 / \mathrm{T}>0.91)$. A small discrepancy between modeled and measured IDT data is observed and grows as initial temperature increases, likely a result of the secondary pyrolysis of C-4 fuel fragments. A maximum difference exists above $1100 \mathrm{~K}(1000 / \mathrm{T}<0.0 .91)$ but remains of order unity.

\section{Conclusion}

As part of the National Jet Fuel Combustion Program initiative to develop fundamental models of suitable low-carbon jet fuel alternatives, the present study represents one step in this larger effort: the pyrolysis characterization and kinetic-model development for one particular test fuel, C-4. C-4, a lowcetane number, broad-boiling fuel, was shock-heated to a range of combustion-relevant conditions and interrogated at nine laser wavelengths during pyrolysis. Species time-histories and early-time yields were 
recovered using a multi-wavelength matrix speciation technique, and the results were used to develop a hybrid-chemistry kinetic model. The model was subsequently evaluated with new experimental ignition delay time measurements of C-4 near 12 atm and displays good agreement. In addition to offering a computational model of C-4 for the alternative jet fuel community, this study offers a systematic method to derive hybrid-chemistry model parameters from experimental pyrolysis measurements. The methodology presented here can be readily extended to any number of additional fuels to develop accurate, computationally efficient kinetic models for a range of practical applications.

\section{Acknowledgments}

This work was funded by the US Federal Aviation Administration (FAA) Office of Environment and Energy as a part of ASCENT Project 25 under FAA Award Number: 13-C-AJFE-SU-016. Any opinions, findings and conclusions or recommendations expressed in this material are those of the authors and do not necessarily reflect the views of the FAA or other ASCENT sponsors. Authors N. H. Pinkowski and S. J. Cassady acknowledge financial support from the Department of Defense through the National Defense Science and Engineering Graduate (NDSEG) Fellowship.

\section{Appendix A}

Absorption cross-section correlations for C-4 are presented in Table A.1. Cross-section measurements used for all correlations were produced from high-temperature shock tube experiments using the measured absorbance immediately following time-zero.

Table A.1. Cross-section correlation table for C-4.

\begin{tabular}{|c|c|c|c|}
\hline Species & $\begin{array}{l}\text { Fitted value of cross-section }\left(\sigma\left[\frac{m 2}{m o l}\right]\right) \text { vs. } \\
\text { temperature }(T[K])\end{array}$ & $\begin{array}{l}\text { Standard error } \\
(n=\# \text { of samples })\end{array}$ & Notes \\
\hline \multicolumn{4}{|c|}{ Cross-sections at $3.1758 \mu \mathrm{m}$} \\
\hline C4 & $\begin{array}{c}\quad=a_{0}+a_{1} T \\
a_{0}=-0.4234 \\
a_{1}=0.00203\end{array}$ & $\begin{array}{l}n=21 \\
v=19 \\
R S S=50.89617 \\
t_{95}=2.093 \\
s_{T T}=2.78 E 6 \\
\bar{T}=724.805\end{array}$ & $\begin{array}{l}\text { Correlation valid between } \\
600-1300 K \text {. }\end{array}$ \\
\hline \multicolumn{4}{|c|}{ Cross-sections at $3.283 \mu \mathrm{m}$} \\
\hline $\begin{array}{ll}C 4 \\
\end{array}$ & $\begin{aligned} & =a_{0}+a_{1} \exp \left(-\frac{T-x_{0}}{b_{1}}\right) \\
a_{0} & =7.62268 \\
a_{1} & =11.26859 \\
b_{1} & =212.79 \\
x_{0} & =283.48138\end{aligned}$ & $\begin{array}{l}n=21 \\
\nu=17 \\
R S S=224.65802 \\
t_{95}=2.110 \\
s_{T T}=2.78 E 6 \\
\bar{T}=724.80\end{array}$ & $\begin{array}{l}\text { Correlation valid between } \\
600-1300 \mathrm{~K} \text {. }\end{array}$ \\
\hline \multicolumn{4}{|c|}{ Cross-sections at $3.3519 \mu \mathrm{m}$} \\
\hline C4 & $\begin{array}{l}\quad=a_{0}+a_{1} T+a_{2} T^{2} \\
a_{0}=39.1197 \\
a_{1}=-0.01162 \\
a_{2}=-4.94786 E-6\end{array}$ & $\begin{array}{l}n=16 \\
v=13 \\
R S S=205.307 \\
t_{95}=2.16 \\
s_{T T}=1.85 E 6 \\
\bar{T}=833.42675\end{array}$ & $\begin{array}{l}\text { Correlation valid between } \\
600-1300 \mathrm{~K} \text {. }\end{array}$ \\
\hline
\end{tabular}




\begin{tabular}{|c|c|c|c|}
\hline \multicolumn{4}{|c|}{ Cross-sections at $3.41 \mu \mathrm{m}$} \\
\hline$\overline{C 4}$ & $\begin{aligned} \quad & =a_{0}+a_{1} T+a_{2} T^{2}+a_{3} T^{3} \\
a_{0} & =52.03922 \\
a_{1} & =-0.05106 \\
a_{2} & =1.04587 E-4 \\
a_{3} & =-5.32737 E-8\end{aligned}$ & $\begin{array}{l}n=33 \\
v=29 \\
R S S=97.33397 \\
t_{95}=2.045 \\
s_{T T}=4.99 E 6 \\
\bar{T}=796.541133\end{array}$ & $\begin{array}{l}\text { Correlation valid between } \\
600-1500 \mathrm{~K} \text {. }\end{array}$ \\
\hline \multicolumn{4}{|c|}{ Cross-sections at $10.532 \mu \mathrm{m}$} \\
\hline$\overline{C 4}$ & $\begin{array}{r}=a_{0}+a_{1} T \\
a_{0}=1.06674 \\
a_{1}=0.00119\end{array}$ & $\begin{array}{l}n=19 \\
v=17 \\
R S S=17.24092 \\
t_{95}=2.110 \\
s_{T T}=1.74 E 6 \\
\bar{T}=793.876\end{array}$ & $\begin{array}{l}\text { Correlation valid between } \\
600-1500 \mathrm{~K} \text {. }\end{array}$ \\
\hline \multicolumn{4}{|c|}{ Cross-sections at $10.675 \mu \mathrm{m}$} \\
\hline$\overline{C 4}$ & $\begin{array}{c}=a_{0}+a_{1} T \\
a_{0}=3.87053 \\
a_{1}=-0.00156\end{array}$ & $\begin{array}{l}n=7 \\
v=5 \\
R S S=3.59571 \\
t_{95}=2.571 \\
s_{T T}=9.81 E 5 \\
\bar{T}=830.5517\end{array}$ & $\begin{array}{l}\text { Correlation valid between } \\
600-1400 K \text {. }\end{array}$ \\
\hline \multicolumn{4}{|c|}{ Cross-sections at $10.958 \mu \mathrm{m}$} \\
\hline$\overline{C 4}$ & $\begin{array}{c}=a_{0}+a_{1} T \\
a_{0}=-0.73551 \\
a_{1}=0.00125\end{array}$ & $\begin{array}{l}n=10 \\
v=8 \\
R S S=1.08109 \\
t_{95}=2.306 \\
s_{T T}=3.10 E 5 \\
\bar{T}=801.205\end{array}$ & $\begin{array}{l}\text { Correlation valid between } \\
600-1400 \mathrm{~K} \text {. }\end{array}$ \\
\hline \multicolumn{4}{|c|}{ Cross-sections at $11.345 \mu \mathrm{m}$} \\
\hline$\overline{C 4}$ & $\begin{array}{c}=a_{0}+a_{1} T \\
a_{0}=-0.4432 \\
a_{1}=09.56862 E-4\end{array}$ & $\begin{array}{l}n=18 \\
\nu=16 \\
R S S=7.37934 \\
t_{95}=2.120 \\
s_{T T}=9.30 E 5 \\
\bar{T}=793.876\end{array}$ & $\begin{array}{l}\text { Correlation valid between } \\
600-1400 K \text {. }\end{array}$ \\
\hline
\end{tabular}

\section{Appendix B}

To inform the choice of laser wavelengths for expected species, the carbon distribution of hightemperature C-4 pyrolysis was measured with the acetylene-fired Stanford Variable Pressure Flow Reactor Facility (see [47]), and 2 ms yield results are shown in Fig. B.1 [44]. This flow reactor facility was used to support previous HyChem models [5-8]. From these data, laser wavelengths were chosen to 
target the major expected species, including methane, ethane, ethylene, propene, and iso-butene. Also shown are laser absorption measurements of the target species and HyChem model predictions at $2 \mathrm{~ms}$. The HyChem model agrees well with both laser absorption and flow reactor data. The methane concentration measured with the flow reactor, artificially high due to flow vitiation, is not shown in Fig. B.1. Trace amounts of additional species, primarily alkynes and dienes, also appear in the flow reactors measurements. These species were not targeted in this work.

Figure B.2 shows the cross-sections for species not considered in multi-wavelength measurements or model development. These species include acetylene, propyne, propadiene, 1,3-butadiene, and 1-butene. The data in Fig. B.2 comes from the PNNL database [45]. In each case, the combination of trace mole fractions and relatively weak absorption cross-sections both precluded the sensitive spectroscopic detection of these species and minimized their expected interference at the chosen laser wavelengths.

\section{References}

[1] ICAO. U.S. Aviation Greenhouse Gas Emissions Reduction Plan. (2015).

[2] Colket M, Heyne J, Rumizen M, Gupta M, Edwards T, Roquemore WM, et al. Overview of the National Jet Fuels Combustion Program. AIAA J 55 (2017) 1087-104.

[3] Law CK. Fuel Options for Next-Generation Chemical Propulsion. AIAA J 50 (2012)19-36.

[4] Edwards JT. Reference Jet Fuels for Combustion Testing. 55th AIAA Aerosp Sci Meet (2017):158.

[5] Xu R, Wang K, Banerjee S, Shao J, Parise T, Zhu Y, et al. A physics-based approach to modeling real-fuel combustion chemistry - II. Reaction kinetic models of jet and rocket fuels. Combust Flame 193 (2018) 520-37.

[6] Wang H, Xu R, Wang K, Bowman CT, Hanson RK, Davidson DF, et al. A physics-based approach to modeling real-fuel combustion chemistry - I. Evidence from experiments, and thermodynamic, chemical kinetic and statistical considerations. Combust Flame 193 (2018) 502_ 19.

[7] Wang K, Xu R, Parise T, Shao J, Movaghar A, Lee DJ, et al. A physics-based approach to modeling real-fuel combustion chemistry - IV. HyChem modeling of combustion kinetics of a bio-derived jet fuel and its blends with a concentional Jet A. Combust Flame 198 (2018) 477-89.

[8] Xu R, Wang K, Banerjee S, Shao J, Parise T, Zhu Y, et al. A physics-based approach to modeling real-fuel combustion chemistry - III. Reaction kinetic model of JP10. Combust Flame 193 (2018) 520-37.

[9] Wang S, Parise T, Johnson SE, Davidson DF, Hanson RK. A new diagnostic for hydrocarbon fuels using 3.41- $\mu \mathrm{m}$ diode laser absorption. Combust Flame 186 (2017) 129-39.

[10] Cassady SJ, Susa AJ, Ferris AM, Strand CL, Hanson RK. A two-wavelength ethylene-absorption temperature diagnostic. Meas Sci Technol 30 (2019) 1-10.

[11] Sur R, Wang S, Sun K, Davidson DF, Jeffries JB, Hanson RK. High-sensitivity interference-free diagnostic for measurement of methane in shock tubes. J Quant Spectrosc Radiat Transf 156 (2015) 80-7.

[12] Ren W, Davidson DF, Hanson RK. IR Laser Absorption Diagnostic for C2H4 in Shock Tube Kinetics Studies. Int J Chem Kinet 129 (2011) 423-32.

[13] Pinkowski NH, Cassady SJ, Davidson DF, Hanson RK. Multi-wavelength speciation of hightemperature 1-butene pyrolysis. Fuel 244 (2019) 269-81.

[14] Stranic I, Hanson RK. Laser absorption diagnostic for measuring acetylene concentrations in shock tubes. J Quant Spectrosc Radiat Transf 142 (2014) 58-65.

[15] Pinkowski NH, Ding Y, Johnson SE, Wang Y, Parise TC, Davidson DF, et al. A multi-wavelength speciation framework for high-temperature hydrocarbon pyrolysis. J Quant Spectrosc Radiat Transf 225 (2019) 180-205.

[16] Parise TC, Davidson DF, Hanson RK. Development of a two-wavelength IR laser absorption 
diagnostic for propene and ethylene. Meas Sci Technol 29 (2018) 1-7.

[17] Spearrin RM, Li S, Davidson DF, Jeffries JB, Hanson RK. High-temperature iso-butene absorption diagnostic for shock tube kinetics using a pulsed quantum cascade laser near $11.3 \mu \mathrm{m}$. Proc Combust Inst 35 (2015) 3645-51.

[18] Ranade R, Alqahtani S, Farooq A, Echekki T. An ANN based hybrid chemistry framework for complex fuels. Fuel 241 (2019) 625-36.

[19] Ranade R, Alqahtani S, Farooq A, Echekki T. An extended hybrid chemistry framework for complex hydrocarbon fuels. Fuel 251 (2019) 276-84.

[20] Pinkowski NH, Davidson DF, Hanson RK. Multi-wavelength speciation of high-temperature alternative and conventional jet fuel pyrolysis. AIAA Scitech Forum (2019):1-9.

[21] Cassady SJ, Peng WY, Hanson RK. Temperature-dependent line parameter study of acetylene transitions near $3 \mu \mathrm{m}$. J Quant Spectrosc Radiat Transf 221 (2018) 172-82.

[22] Goldenstein CS, Spearrin RM, Jeffries JB, Hanson RK. Infrared laser-absorption sensing for combustion gases. Prog Energy Combust Sci 60 (2017) 132-76.

[23] K. Hanson R, Spearrin R, Goldenstein C. Spectroscopy and Optical Diagnostics for Gases. Springer International Publishing, Switzerland. 2016.

[24] Hanson RK, Davidson DF. Recent advances in laser absorption and shock tube methods for studies of combustion chemistry. Prog Energy Combust Sci 44 (2014) 103-14.

[25] Hanson RK, Davidson DF. Advances in shock tube techniques for fundamental studies of combustion kinetics. 25th ICDERS (2015) 1-5.

[26] Strand CL, Ding Y, Johnson SE, Hanson RK. Measurement of the mid-infrared absorption spectra of ethylene (C2H4) and other molecules at high temperatures and pressures. J Quant Spectrosc Radiat Transf 222-223 (2018) 122-9.

[27] Cao Y. Ignition Delay Time Measurements for Distillate and Synthetic Jet Fuels. Stanford University, Thesis for the Degree of Engineer (2018).

[28] Shao J, Choudhary R, Davidson DF, Hanson RK, Barak S, Vasu S. Ignition delay times of methane and hydrogen highly diluted in carbon dioxide at high pressures up to $300 \mathrm{~atm}$. Proc Combust Inst 000 (2018) 1-8.

[29] Campbell MF, Haylett DR, Davidson DF, Hanson RK. AEROFROSH: a shock condition calculator for multi-component fuel aerosol-laden flows. Shock Waves 26 (2016) 429-47.

[30] Gauthier BM, Davidson DF, Hanson RK. Shock tube determination of ignition delay times in fullblend and surrogate fuel mixtures. Combust Flame 139 (2004) 300-11.

[31] MacDonald ME, Ren W, Zhu Y, Davidson DF, Hanson RK. Fuel and Ethylene Measurements during n-dodecane, methylcyclohexane, and iso-cetane pyrolysis in shock tubes. Fuel 103 (2013) 1060-8.

[32] Parise TC. Shock Tube and Laser Absorption Studies of Small Alkane Spectroscopy and Real Fuel Kinetics. Stanford University, Doctoral Thesis (2018).

[33] Grant M, Boyd S. CVX: Matlab software for disciplined convex programming, version 2.0 beta. Available at: http://cvxr.com/cvx n.d.

[34] Grant M, Boyd SP. Graph implementations for nonsmooth convex programs, Recent Advances in Learning and Control (a tribute to M. Vidyasagar), V. Blondel, S. Boyd, and H. Kimura, editors,. Springer International Publishers, Swizterland. (2008) 95-110.

[35] Corporan E, Edwards JT, Stouffer S, DeWitt M, West Z, Klingshirn C, et al. Impacts of Fuel Properties on Combustor Performance, Operability and Emissions Characteristics, AIAA Scitech Forum (2017) 1-19.

[36] Dooley S, Hee S, Heyne J, Farouk TI, Ju Y, Dryer FL, et al. The experimental evaluation of a methodology for surrogate fuel formulation to emulate gas phase combustion kinetic phenomena. Combust Flame 159 (2012) 1444-66.

[37] Dryer FL, Jahangirian S, Dooley S, Won SH, Heyne J, Iyer VR, et al. Emulating the Combustion Behavior of Real Jet Aviation Fuels by Surrogate Mixtures of Hydrocarbon Fluid Blends : Implications for Science and Engineering. Energy and Fuels 28 (2014) 3474-85. 
[38] B. Sirjean E, Dames DA, Sheen X-Q, You C, Sung AT, Holley FN, et al. A high-temperature chemical kinetic model of n-alkane oxidation, JetSurF version 1.0, 2009. Available at: http://web.stanford.edu/group/haiwanglab/JetSurF.

[39] Wang H, Dames E, Sirjean B, Sheen DA, Tangko R, Violi A, et al. A high-temperature chemical ki- netic model of $\mathrm{n}$-alkane (up to $\mathrm{n}$-dodecane), cyclohexane, and methyl-, ethyl- , $\mathrm{n}$-propyl and $\mathrm{n}$-butyl-cyclohexane oxidation at high temperatures, JetSurF version 2.0, 2010 Available at: http://web.stanford.edu/group/haiwanglab/JetSurF.

[40] Goodwin DG, Speth RL, Moffat HK, Weber BW. Cantera: An Object-oriented Software Toolkit for Chemical Kinetics, Thermodynamics, and Transport Processes 2018. https://cantera.org

[41] Xu R, Wang H, Colket M, Edwards T. Thermochemical Properties of Jet Fuels. 2015. Available at: https://web.stanford.edu/group/haiwanglab/HyChem/approach/.

[42] Wang H. Personal Communication 2019.

[43] Melguizo-Gavilanes J, Bauwens L. On the Validity of the Constant Volume Assumption in Shock Tube Experiments. In: Kontis K, editor. 28th Int. Symp. Shock Waves, Berlin, Heidelberg: Springer Berlin Heidelberg; (2012) 179-84.

[44] Banerjee S. Personal Communication 2015.

[45] Sharpe SW, Johnson TJ, Sams RL, Chu PM, Rhoderick GC, Johnson PA. Gas-Phase Databases for Quantitative Infrared Spectroscopy. Appl Spectrosc 58 (2004) 1452-61.

[46] Davidson, David F. and Hanson, Ronald K. (2019). Fundamental Kinetics Database Utilizing Shock Tube Measurements. Stanford Digital Repository. Available at: http://purl.stanford.edu/kb621cw6967

[47] Banerjee S, Rei T, Sheen D, Wang H, Bowman CT. An experimental and kinetic modeling study of n-dodecane pyrolysis and oxidation. Combust Flame 163 (2016) 12-30.

\section{Figures}

a)

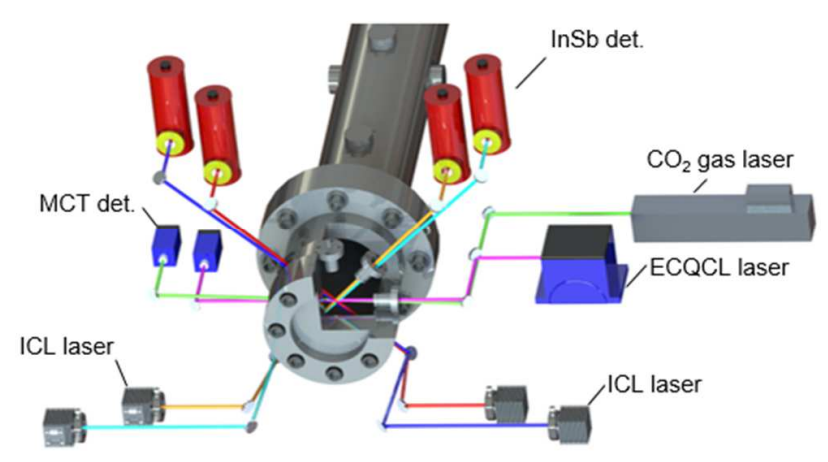

b)

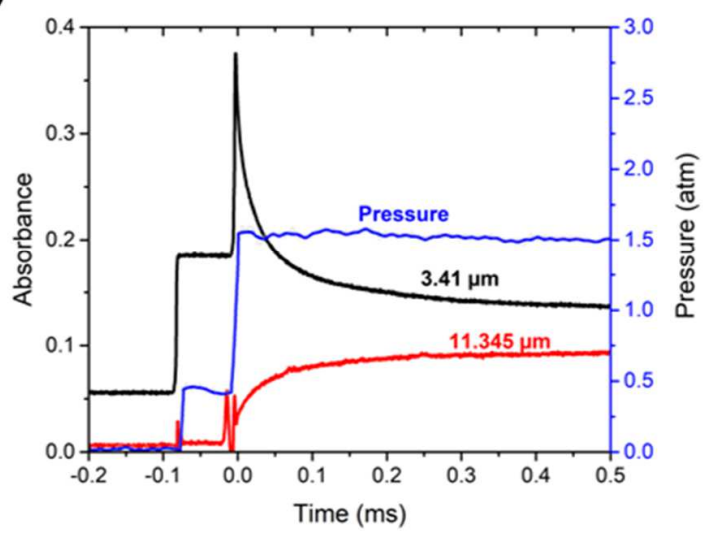

Fig. 1. (a) A representative schematic of lasers aligned through the measurement plane of a shock tube facility, and (b) a representative plot of absorbance time-histories collected during the pyrolysis of $0.4 \%$ $\mathrm{C}-4$ fuel in Ar at an initial temperature of $1304 \mathrm{~K}, 1.53 \mathrm{~atm}$. The wavelengths shown, $3.41 \mu \mathrm{m}$ (black) and $11.345 \mu \mathrm{m}$ (red), are highly sensitive to fuel and iso-butene, respectively. 
a)

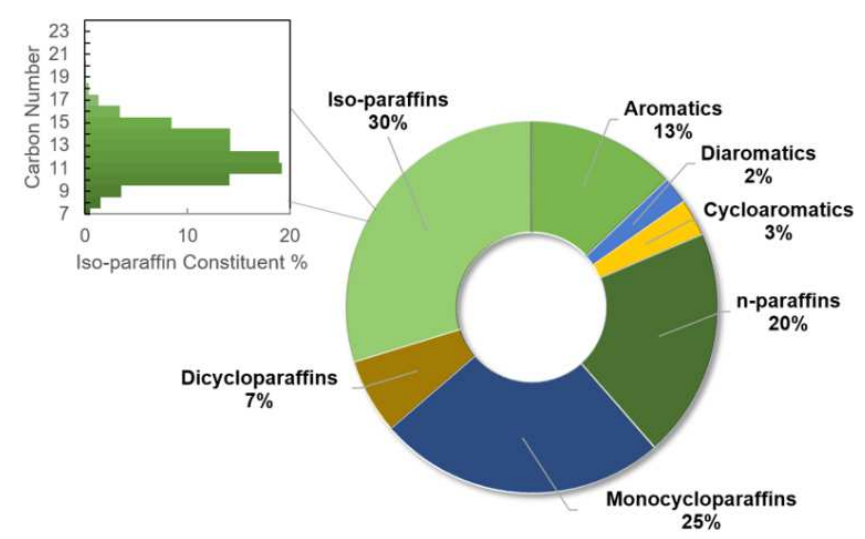

b)

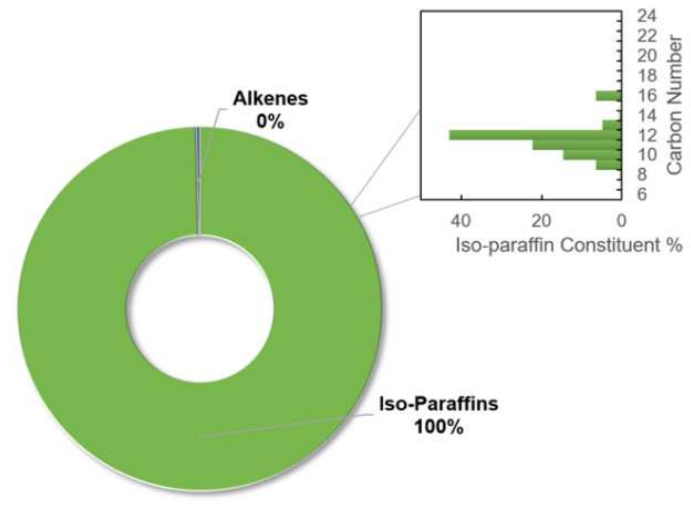

Fig. 2. Comparative fuel compositions of (a) Jet A (A-2) and (b) C-4 from [4]. C-4's choice as an "unusual" test fuel with a unique chemical composition is evident.

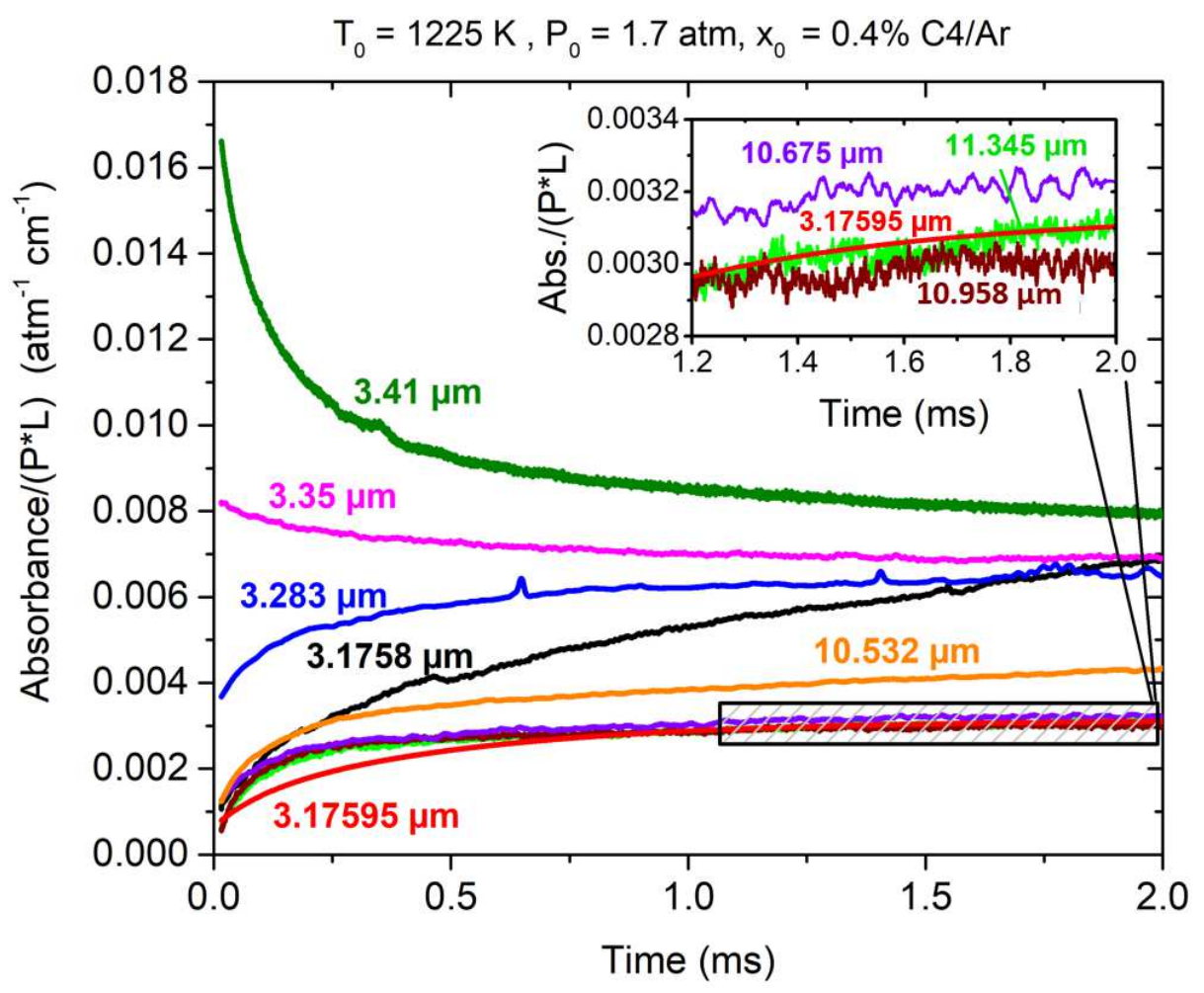

Fig. 3. Pressure- and path length-normalized absorbance traces produced at $1225 \mathrm{~K}$ through an interpolation of shock tube experiments. The measured absorbance at each wavelength arises from the composite absorption of each species present in the system. Each laser wavelength shown in the figure and in Table 1 targets unique absorption features of individual species forming or decomposing during pyrolysis. 
a)
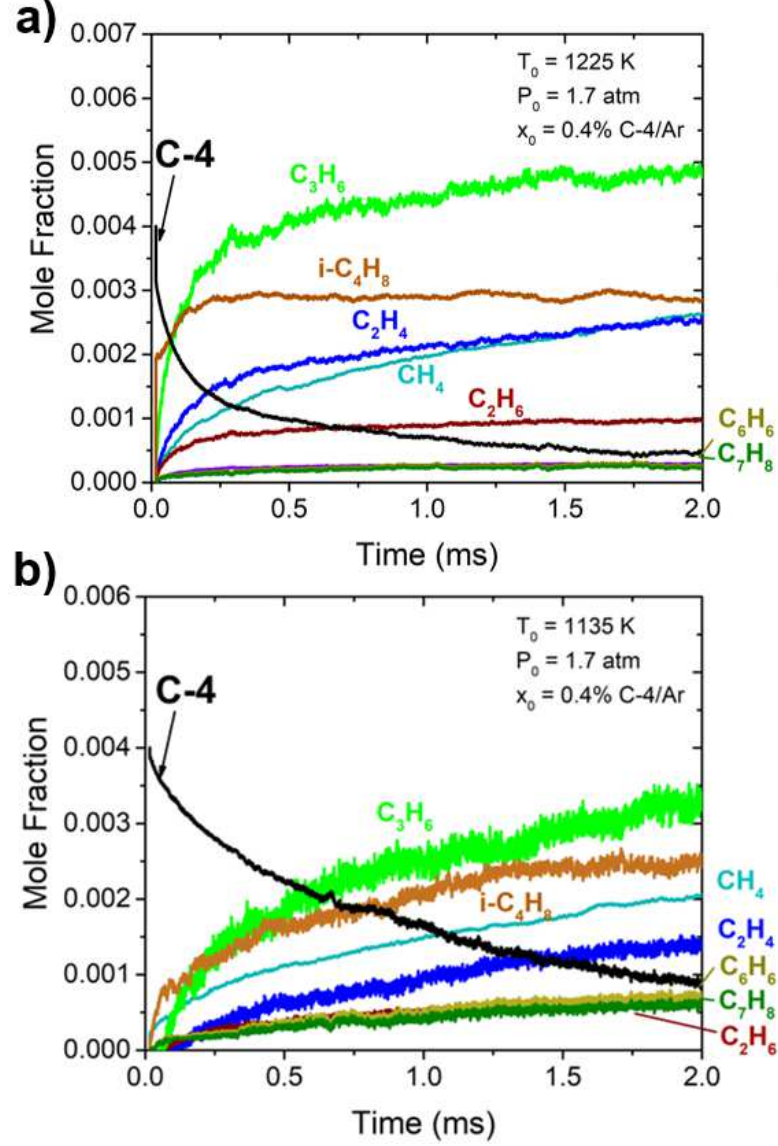

c)

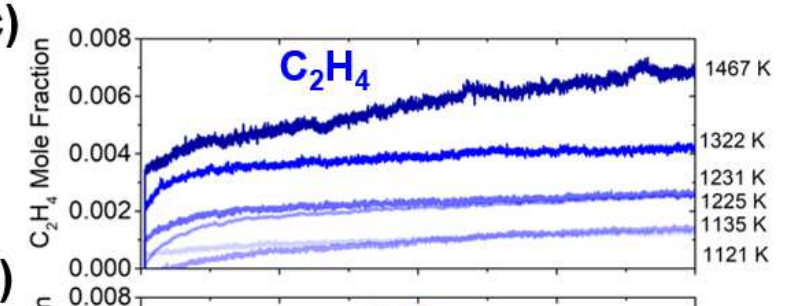

d)

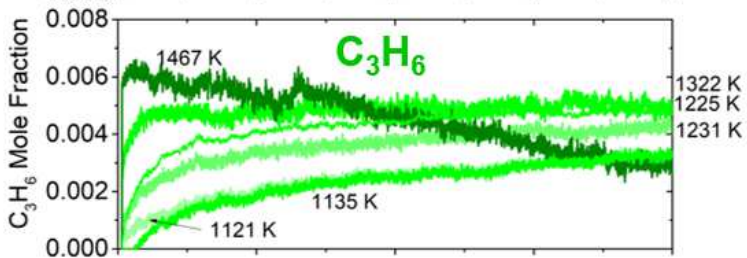

e)

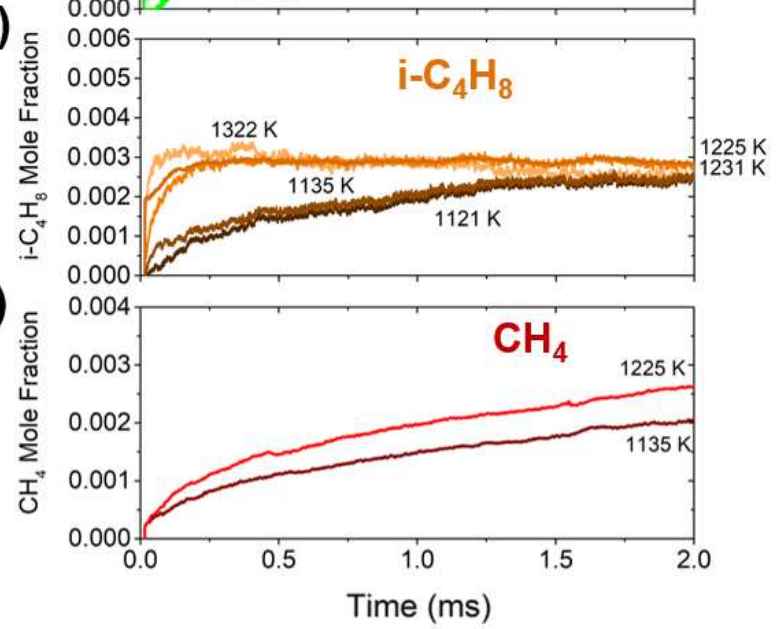

Fig. 4. Representative mole fraction measurements at conditions of $\mathrm{T}=1120-1470 \mathrm{~K}, \mathrm{P}=1.4-1.7 \mathrm{~atm}$, and $x_{0}=0.4 \% \mathrm{C}-4 / \mathrm{Ar}$ showing two demonstrative conditions (left) and the major species (right): a) eight species at $1225 \mathrm{~K}$, b) 8 species at $1135 \mathrm{~K}$, c) multi-temperature measurements of ethylene, d) propene, e) iso-butene, and f) methane. 


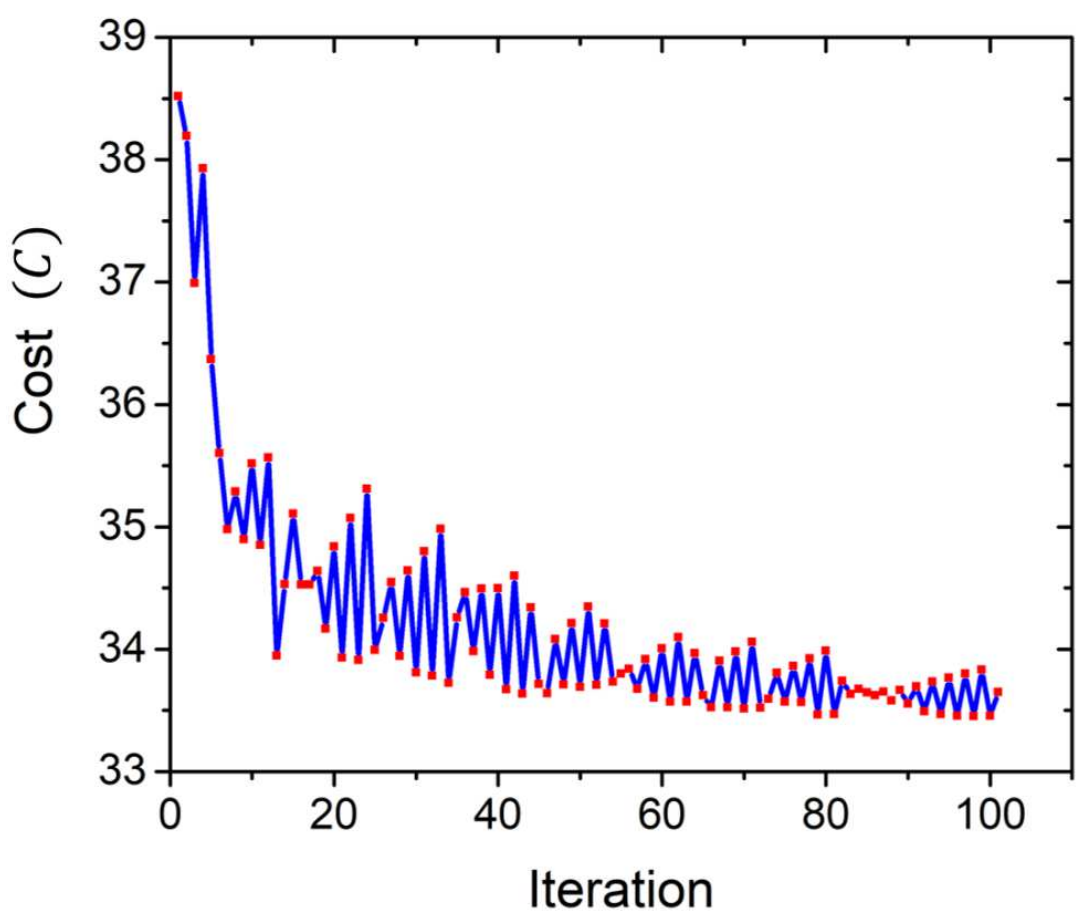

Fig. 5. Convergence curve of the batch gradient descent model optimization process over 100 iterations. 
a)

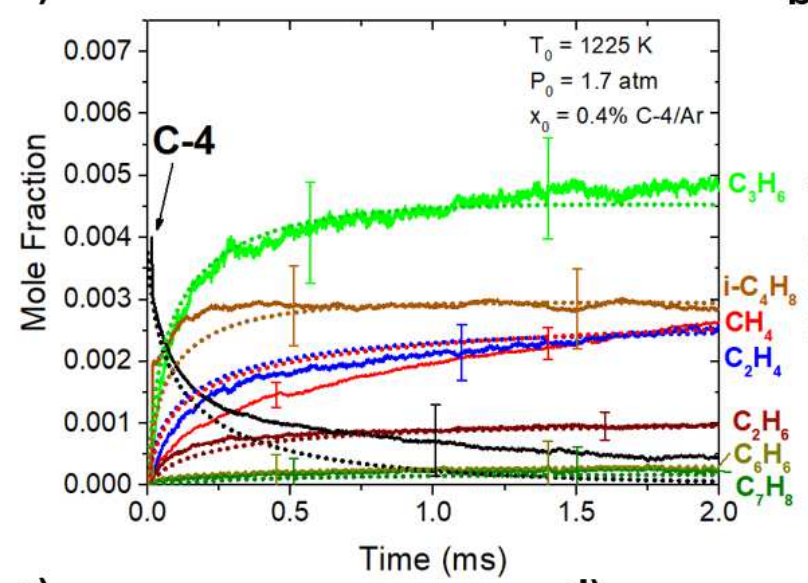

c)

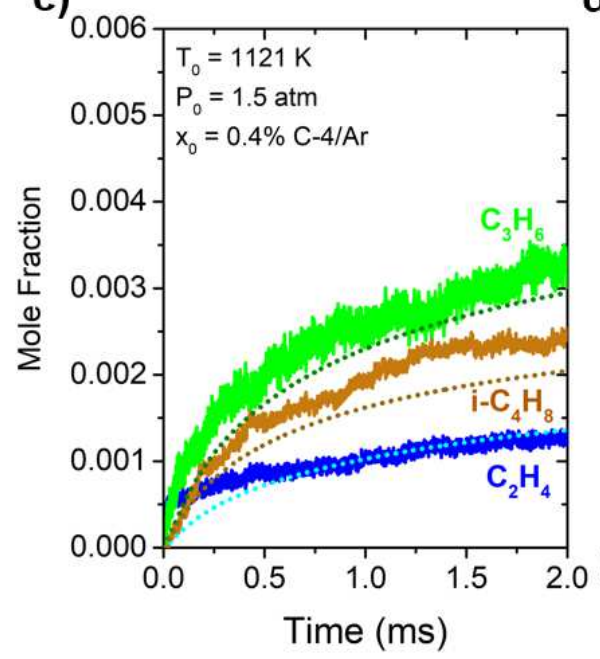

b)

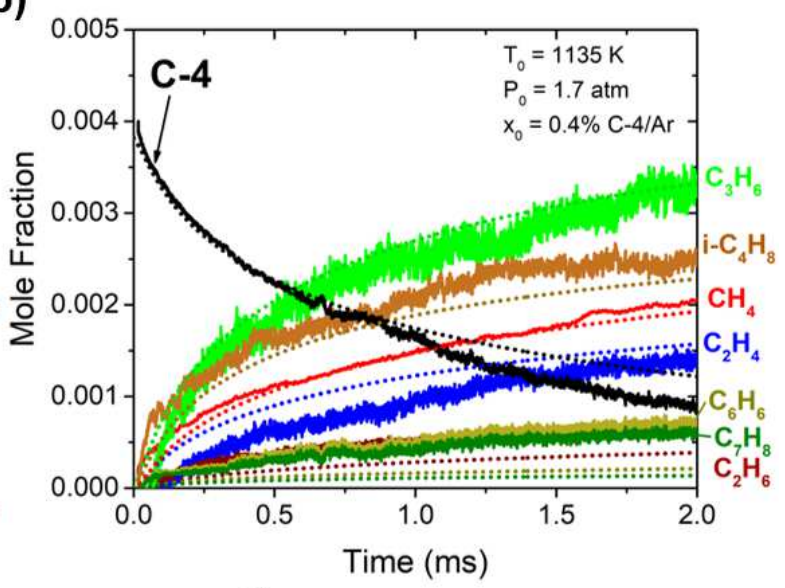

e)
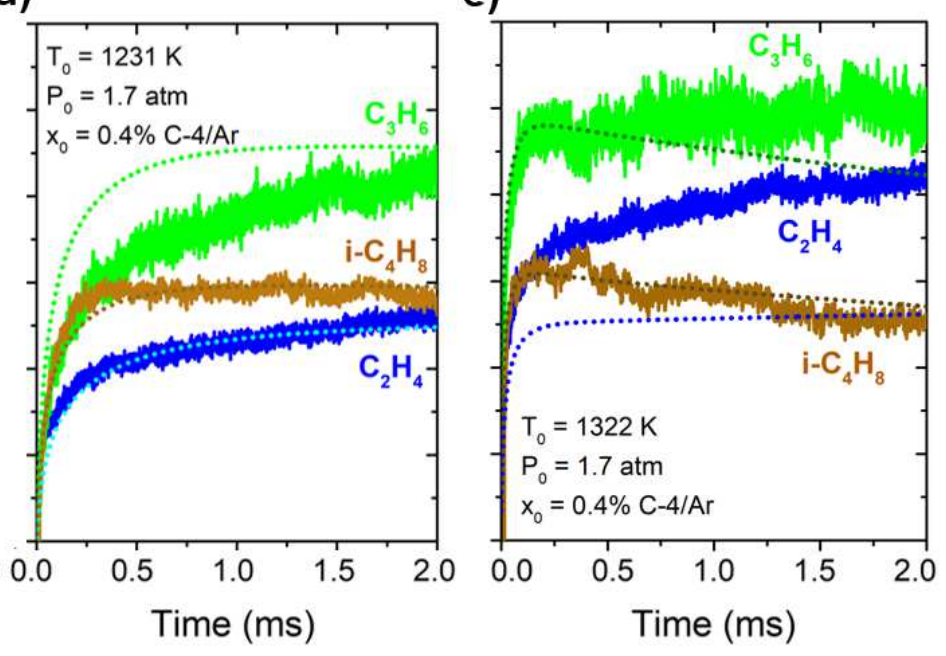

Fig. 6. Comparisons of modeled and measured time-histories for C-4 pyrolysis at five experimental test conditions (a-e). Representative 1-sigma uncertainties are shown in (a). 


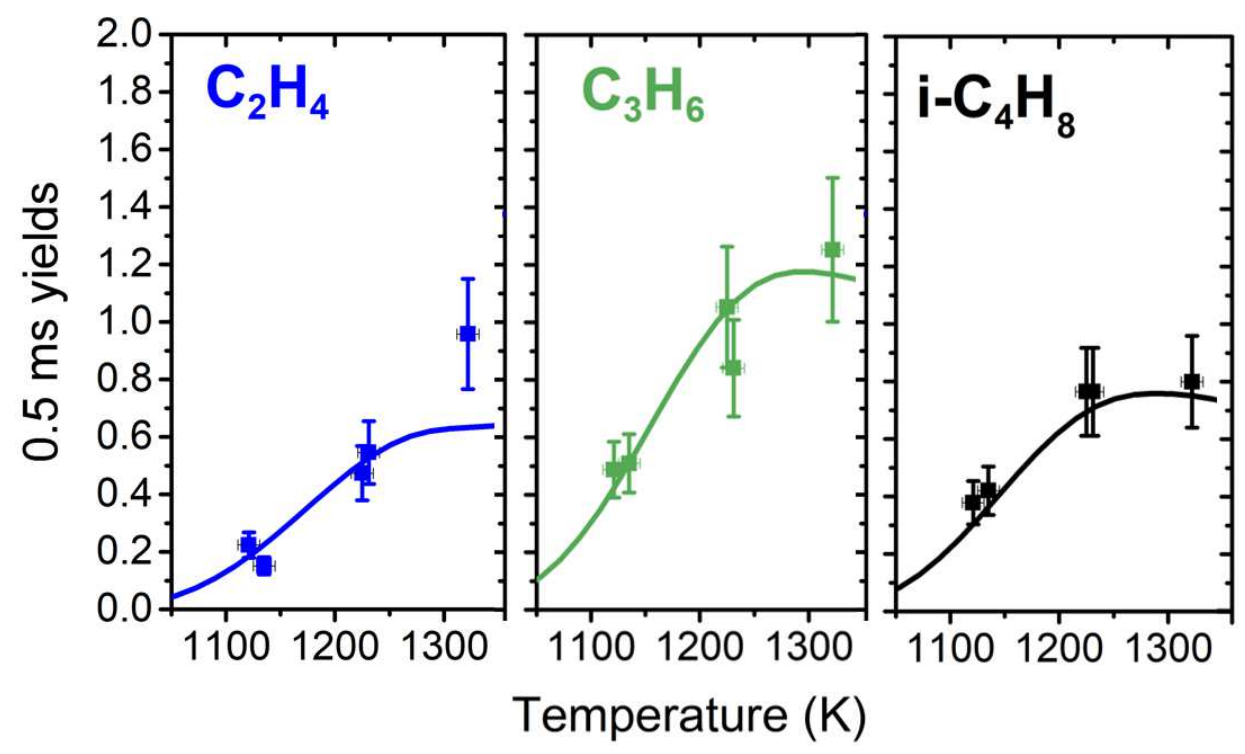

Fig. 7. A comparison of modeled versus measured species yields at $0.5 \mathrm{~ms}$ for ethylene $\left(\mathrm{C}_{2} \mathrm{H}_{4}\right.$, left), propene $\left(\mathrm{C}_{3} \mathrm{H}_{6}\right.$, center), and iso-butene $\left(\mathrm{i}-\mathrm{C}_{4} \mathrm{H}_{8}\right.$, right). Yields are defined as the mole fraction of each species at $0.5 \mathrm{~ms}$ normalized by the mole fraction of $\mathrm{C}-4$ at time-zero.

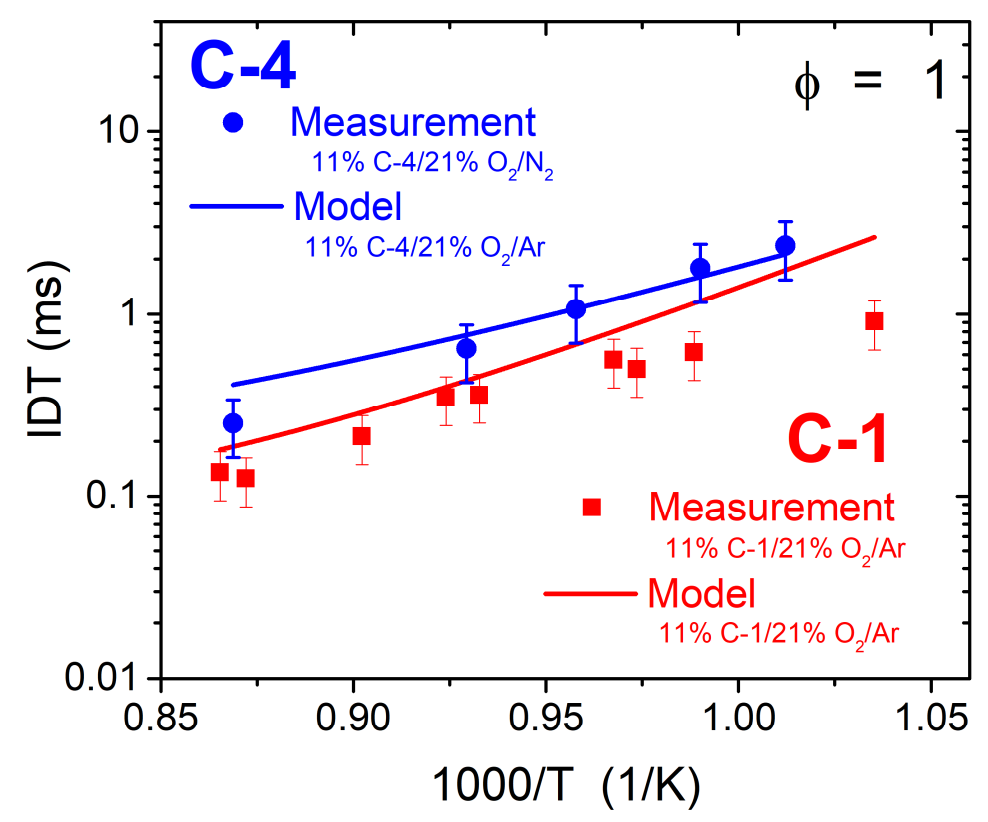

Fig. 8. A comparison between the modeled and measured ignition delay time (IDT) for $11 \% \mathrm{C}-4 / 21 \% \mathrm{O}_{2}$ $(\phi=1)$ at $12 \mathrm{~atm}$. Also shown are measured and modeled IDT for C-1 fuel at $16 \mathrm{~atm}$, in red [46]. Good agreement is observed between the measurements and the model. 


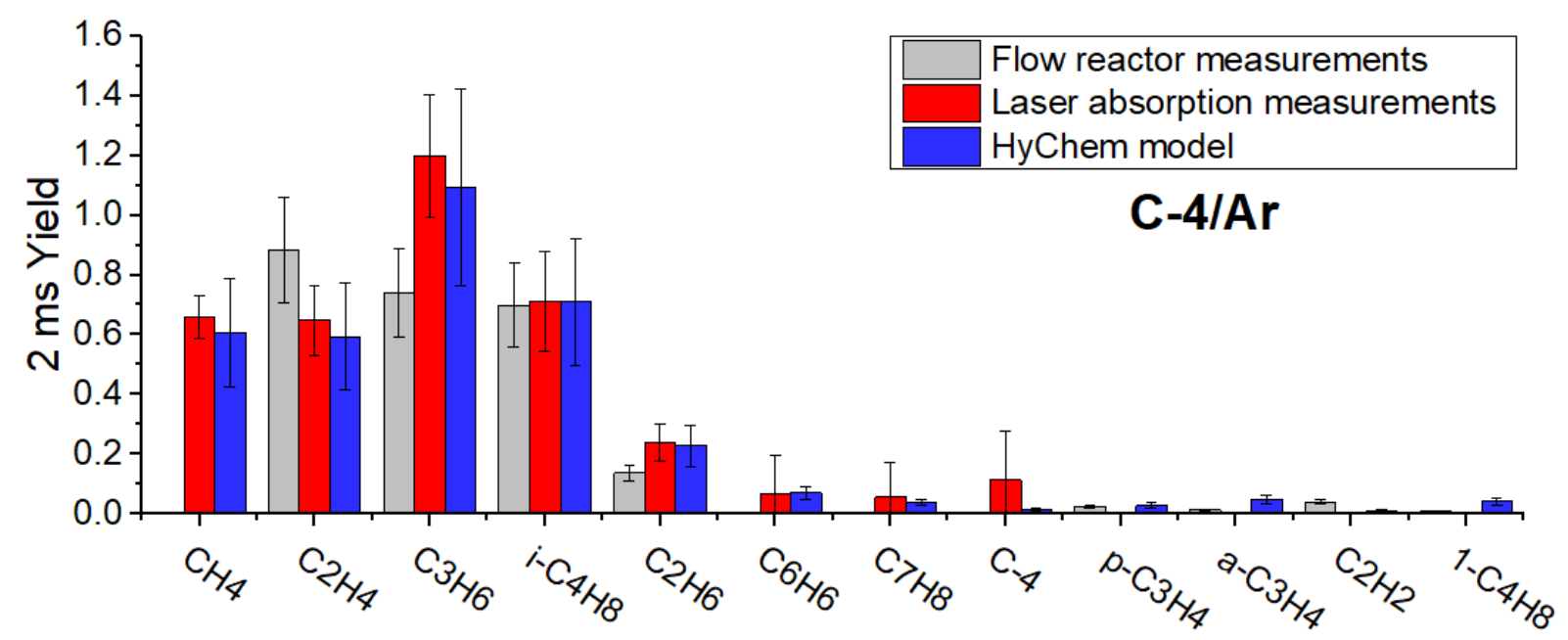

Fig. B.1. Flow reactor species yields at $2 \mathrm{~ms}$ of $302 \mathrm{ppmv}$ C-4/Ar pyrolysis at $1140 \mathrm{~K}, 1 \mathrm{~atm}$ (gray), compared with laser absorption-based speciation values at $1225 \mathrm{~K}, 1.6 \mathrm{~atm}$, with $0.4 \% \mathrm{C}-4 / \mathrm{Ar}$ (red) and HyChem model predictions at $1225 \mathrm{~K}, 1.6 \mathrm{~atm}$ (blue). Here, yield is defined as species mole fractions normalized by the initial fuel mole fraction. Good agreement is observed between the model and both sets of measurements. Flow reactor uncertainty was taken as $20 \%$.

a)

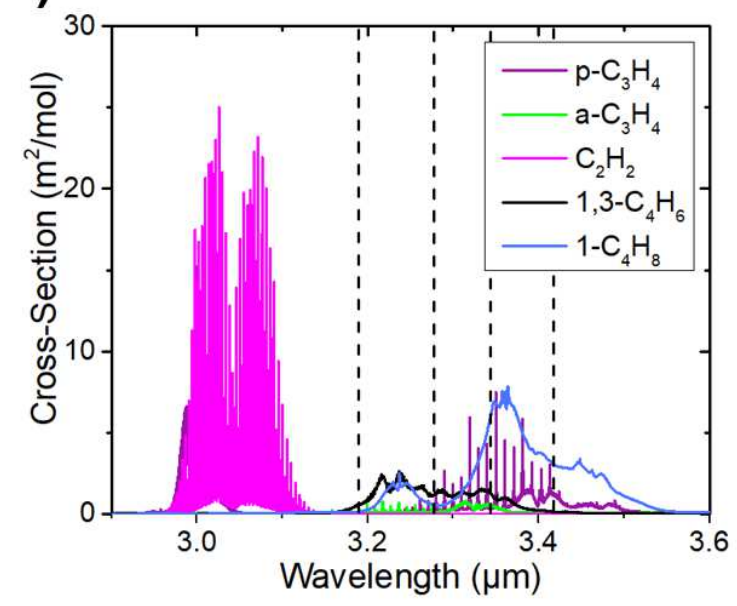

b)

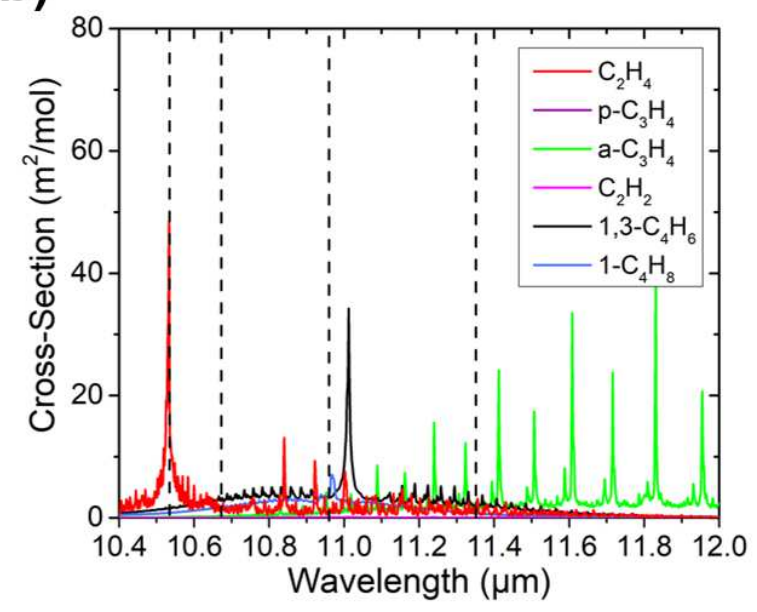

Fig. B.2. Absorption cross-sections of expected interferers not quantified with the present measurements, at $323 \mathrm{~K}, 1 \mathrm{~atm}$ [45]. Also shown is ethylene for reference. These species are included in the measurements.

\section{Algorithms}

Algorithm 1. Search strategy for optimal hybrid-chemistry parameters $\boldsymbol{y}^{*}$. 


\footnotetext{
Result: Optimal parameters $y^{*}$

initialization: guess $y^{(0)}$

for $i$ from 1 to iter $r_{\max }$ do

1. build HyChem mechanism with parameters $y^{(i-1)}$

2. evaluate cost for the current $\mathrm{HyChem}$

3. evaluate gradient numerically $C^{\prime}=\left.\nabla_{y} C\right|_{y^{(i-1)}}$

4. calculate learning rate $\psi=0.25 \exp \left\{-i /\right.$ iter $\left._{\max }\right\}$

5. update parameters $y$ by $\ln y^{(i)}=\ln y^{(i-1)}-\ln \left(1-\operatorname{sign}\left(C^{\prime}\right) \cdot \psi\right)$ end

set $y^{*}=y^{\left(\text {iter }_{\max }\right)}$
} 
Technical Report Documentation Page

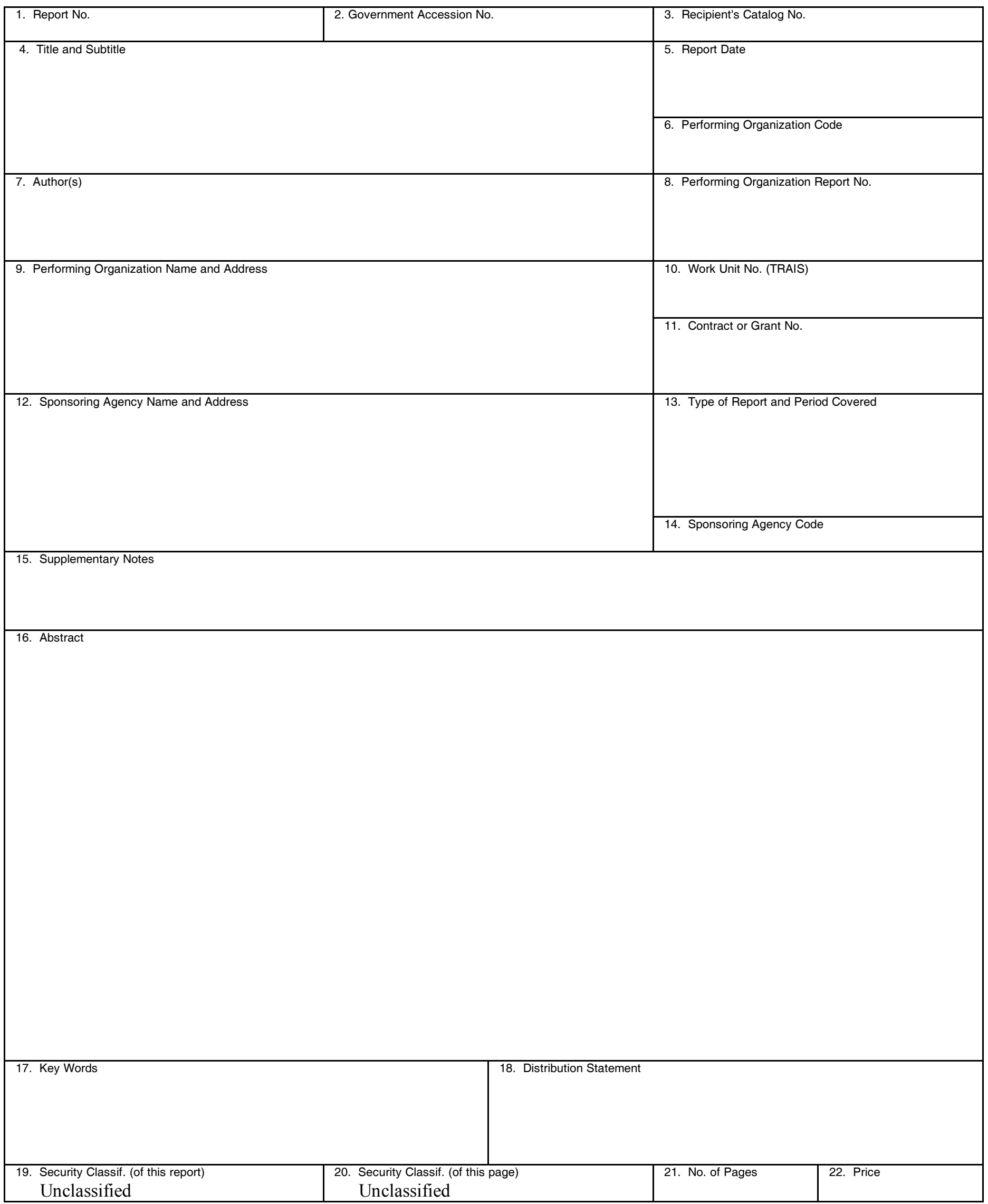

Form DOT F 1700.7 (8-72) Reproduction of completed page authorized

